\title{
Projeto de um Estimador de Potência para o Processador Nios II da Altera
}

\author{
José Arnaldo Mascagni de Holanda
}

Orientador: Prof. Dr. Eduardo Marques

Dissertação apresentada ao Instituto de Ciências Matemáticas e de Computação - ICMC-USP, como parte dos requisitos para obtenção do título de Mestre em Ciências - Ciências de Computação e Matemática Computacional.

USP - São Carlos

Março de 2007 
Projeto de um Estimador de Potência para o Processador Nios II da Altera 



\section{Agradecimentos}

A Deus, por Sua bondade e fidelidade dia após dia;

Aos meus pais José Dantas e Vilza, a minha irmã Juliana e aos demais parentes, pelo apoio e por serem uma grande benção em minha vida;

Ao meu orientador Eduardo Marques, pelos conselhos, por ensinar com paciência e pelo constante bom humor;

Aos colegas do LCR, em especial ao Vanderlei, ao Carlos, ao Jecel e ao Denis, pelos conhecimentos compartilhados e pelos momentos de descontração;

Aos colegas do Grupo de Instrumentação e Informática, em especial ao Lírio, por estarem sempre dispostos a ajudar e pela preciosa contribuição na realização deste trabalho;

Ao João Cardoso, por sempre apontar as direções certas;

Aos demais amigos e colegas, sejam do curso de mestrado ou não, pelo companheirismo durante esses anos.

E, por fim, ao CNPq pelo apoio financeiro. 



\section{Resumo}

Atualmente, otimizar uma arquitetura ou um sistema de software não significa, necessariamente, aumentar o seu desempenho computacional. Devido a popularização de sistemas embutidos energizados por bateria, um item de grande importância a ser otimizado é o consumo de energia. De forma a obedecer às restrições de consumo, pesquisadores têm concentrado seus esforços na criação de ferramentas que possibilitam a modelagem, a otimização e a estimação do consumo de energia. Nos últimos anos, FPGAs têm apresentado um grande desenvolvimento nos quesitos densidade, velocidade e capacidade de armazenamento. Essas características tornaram possível a construção de sistemas complexos formados por um ou mais processadores soft-core. Esse tipo de processador permite uma personalização detalhada de suas características arquiteturais, possibilitando uma melhor adequação às restrições de tempo e espaço em um projeto. O objetivo deste trabalho é construir um estimador de potência para softwares que têm como alvo o processador soft-core Nios II da Altera, permitindo saber com antecedência quanta energia será consumida devido à execução de programas e aplicações de robótica móvel. O modelo implementado neste trabalho foi testado com vários benchmarks padronizados e os resultados obtidos provaram ser bastante adequados para estimar a energia consumida por um programa, obtendo erros de estimação máximos de 4,78\%, 



\section{Abstract}

Nowadays, optimization of hardware and software systems does not necessarily mean increasing their computational performance. Due to the popularization of battery-operated embedded systems, energy comsumption has become a very critical issue. Several tools have been created to model, optimize, and estimate energy consumption, allowing power constraints to be achieved. Lately, FPGAs have presented great advancements on density, speed and storage capacity. Such characteristics made possible the implementation of complex systems comprising one or more soft-core processors. This kind of processors allows detailed customization of its architectural features, enabling timinig, and area constraints of a design to be reached. The aim of this work is to build a power estimator to predict the energy comsumption of a software running on the Altera Nios II soft-core processor. The implemented estimation model presented on this dissertation has been tested with several standard benchmarks and the results obtained have proven to be suitable for estimating the energy consumption of a software with a maximum error of $4.78 \%$. 



\section{Índice}

Lista de Figuras $\quad$ xii

Lista de Tabelas $\quad$ xiii

1 Introdução 1

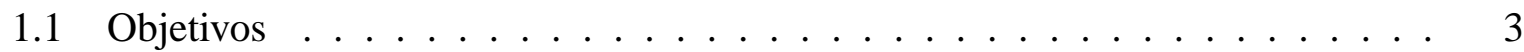

1.2 Organização do Trabalho . . . . . . . . . . . . . . . . . . . 4

2 Computação Reconfigurável 5

2.1 Hardware Reconfigurável . . . . . . . . . . . . . . . . . . . . . 6

2.1.1 FPGAs de última geração . . . . . . . . . . . . . . . . . . 8

2.2 Ferramentas EDA . . . . . . . . . . . . . . . . . . 10

2.3 Processador Nios II . . . . . . . . . . . . . . . . . . . 12

2.3.1 Conjunto de Instruções . . . . . . . . . . . . . . . . . . . . . . 13

3 Estimação e Dissipação de Potência $\quad 15$

3.1 Dissipação de potência em FPGAs . . . . . . . . . . . . . . . . . 15

3.1.1 Fatores que afetam a dissipação de potência . . . . . . . . . . . . . 17

3.1.2 Ferramentas de Análise e Estimação de Potência . . . . . . . . . . . . 20

3.1 .3 Considerações . . . . . . . . . . . . . . . . 25

3.2 Estimadores de Potência . . . . . . . . . . . . . . . . . 25

3.2 .1 JouleTrack . . . . . . . . . . . . . . . . . 26

3.2 .2 SimplePower . . . . . . . . . . . . . . . . 27

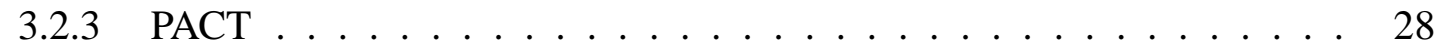

3.2.4 Outros Trabalhos Relacionados . . . . . . . . . . . . . . 29

4 Implementação e Resultados

4.1 Metodologia . . . . . . . . . . . . . . . . . . 37

4.1.1 Instrumentação e Configuração do Hardware . . . . . . . . . . . . . . 39 
4.1 .2 Configuração do Software . . . . . . . . . . . . . . . . . 44

4.1 .3 Medições . . . . . . . . . . . . . . . . . . . . . . . 47

4.2 Análise dos Resultados . . . . . . . . . . . . . . . . . . . . 48

$4.2 .1 \quad$ Nios II Economic . . . . . . . . . . . . . . . . . . . . . 49

4.2 .2 Nios II Standard . . . . . . . . . . . . . . . . . . 51

5 Conclusão $\quad 57$

5.1 Trabalhos Futuros . . . . . . . . . . . . . . . 58

$\begin{array}{ll}\text { Referências Bibliográficas } & 58\end{array}$

$\begin{array}{ll}\text { Apêndice A } & 62\end{array}$ 


\section{Lista de Figuras}

2.1 Evolução do número de transistores através do tempo . . . . . . . . . . . . 6

2.2 Chips disponíveis para implementação de circuitos lógicos (Hamblen e Furman,

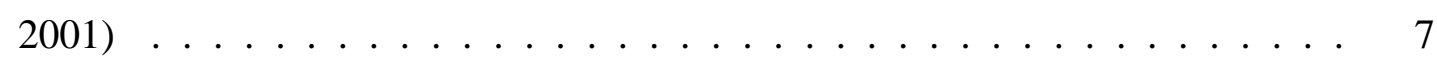

2.3 Relação entre as diferentes tecnologias de hardware (Hamblen e Furman, 2001) 8

2.4 Fluxo padrão de projeto para a ferramenta Quartus II (Altera, 2005b) . . . . . . 11

2.5 Diagrama de blocos do core do processador Nios II (Altera, 2005a) . . . . . . . 13

3.1 Relacionamento entre a potência estática e a temperatura do FPGA . . . . . . . 16

3.2 Precisão da estimação, em relação as fases do projeto . . . . . . . . . . . . . . 21

3.3 Fluxo de projeto com otimização de energia da ferramenta PowerPlay . . . . . 23

3.4 Planilha do PowerPlay Early Power Estimator . . . . . . . . . . . . . . . 32

3.5 Consumo de corrente para benchmarks sendo executados no processador StrongARM a diferentes frequiências de operação . . . . . . . . . . . . . . . . . 33

3.6 Diagrama de blocos da ferramenta JouleTrack . . . . . . . . . . . . . . 33

3.7 Framework de estimação de energia SimplePower . . . . . . . . . . . . . . . 34

3.8 Inter-realação entre as tarefas do PACT . . . . . . . . . . . . . 35

4.1 Visão detalhada da Nios II Evaluation Board . . . . . . . . . . . . . . . . . . . 40

4.2 Função dos pinos do módulo Firefly . . . . . . . . . . . . . . . . . . 41

4.3 Extensão para interceptação dos pinos do módulo Firefly . . . . . . . . . . . 42

4.4 Setup para medições de corrente . . . . . . . . . . . . . . . . . . 42

4.5 Lista de periféricos presentes em ambos os sistemas Economic e Standard . . . 43

4.6 Programa para traçar o perfil de consumo de corrente da instrução ADD. . . . . 45

4.7 Medição da variação de corrente da instrução cmpge para o núcleo Economic 48

4.8 Medição da variação de corrente da instrução cmpge para o núcleo Standard . . 49

4.9 Consumo médio de corrente para cada instrução do núcleo Economic . . . . . . 49

4.10 Consumo de corrente dos programas de teste em função da frequiência para o núcleo Economic . . . . . . . . . . . . . . . . . . . . . . . 50 
4.11 Consumo médio de corrente para cada instrução do núcleo Standard . . . . . . 52

4.12 Consumo de corrente dos programas de teste em função da freqüência para o núcleo Standard . . . . . . . . . . . . . . . . . . . . . . . . 52

4.13 Comparação entre os consumos de corrente real e estimado para o núcleo Standard 54

4.14 Comparação entre os consumos de corrente real, estimado e estimado com fator de ajuste. . . . . . . . . . . . . . . . . . . . 54 


\section{Lista de Tabelas}

2.1 Variação do número de elementos lógicos nos dispositivos de cada família de FPGAs da Altera e estimativa do número máximo de cores do processador Nios II standard no FPGA . . . . . . . . . . . . . . . . . . . . . . . 9 9

2.2 Variação do número de células lógicas em cada sub-família da família Virtex-5 10

3.1 Resistência térmica em dispositivos EP1S10 da família Stratix, da Altera . . . . 19

3.2 Comparação entre as ferramentas PowerPlay Early Power Estimator e PowerPlay Power Analyzer . . . . . . . . . . . . . . . . . . . . . . . 22

4.1 Média de consumo e erro associado dos programas de teste do núcleo Economic 51

4.2 Média de consumo e erro associado dos programas de teste do núcleo Standard 53

4.3 Comparação entre os valores de corrente reais e estimadas dos programas de teste do núcleo Standard . . . . . . . . . . . . . . . . . . . . . . . . . . 53

4.4 Comparação entre os valores de corrente reais e estimadas dos programas de teste do núcleo Standard, utilizando o fator de ajuste. . . . . . . . . . . . . 55 



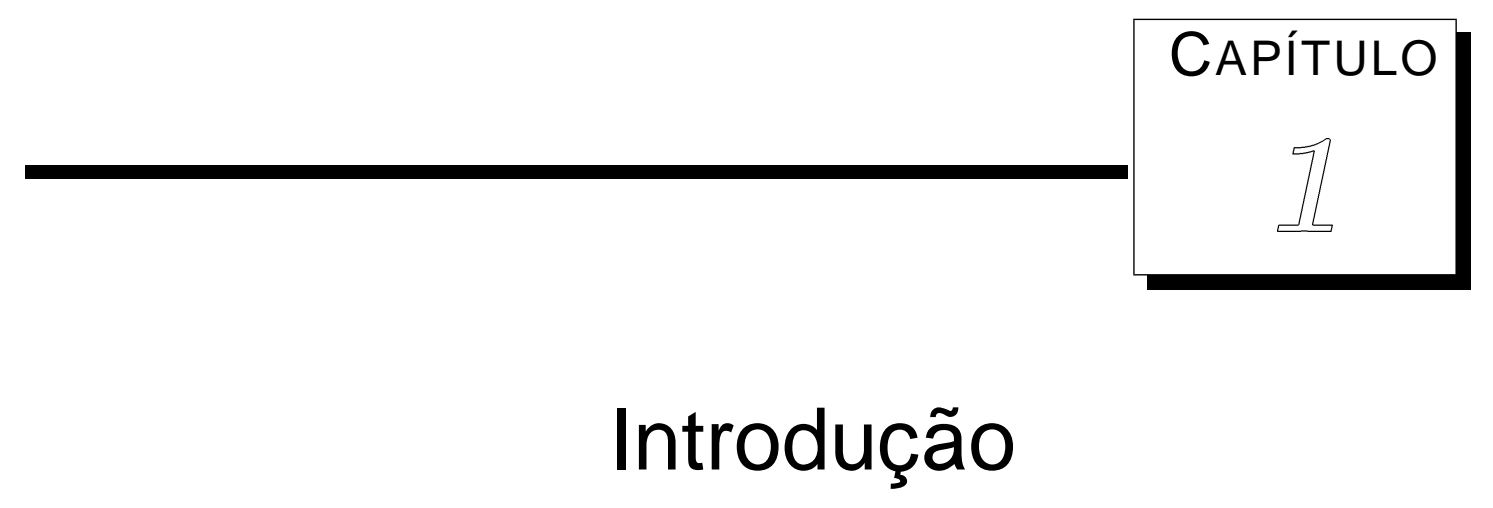

Geralmente, quando se deseja realizar otimizações sobre uma arquitetura ou sistema de software, o primeiro item que vem à mente de um projetista é aumentar o desempenho computacional, ou a velocidade de execução desse sistema. Para isto, alguns fatores arquiteturais são considerados, tais como freqüência de clock, densidade do chip e número de estágios do pipeline. Aumentos de desempenho podem ser obtidos também via software, de modo a obter o máximo de cada ciclo. Contudo, devido à utilização cada vez maior de sistemas embutidos sem fio e alimentados por bateria, como celulares e hand helds, um item de grande importância a ser otimizado é o consumo de energia. De forma a obedecer às restrições de consumo, pesquisadores têm concentrado seus esforços na criação de ferramentas que possibilitam a modelagem, a otimização e a estimação do consumo de energia. Essas ferramentas permitem visualizar, durante as fases iniciais do projeto, o comportamento do consumo de um sistema.

Diversos modelos e metodologias foram propostos para a estimação do consumo de energia e dissipação de potência em processadores. Esses modelos buscam atuar em diferentes níveis de abstração, como são exemplos o nível de circuito (Chen et al., 1998), de portas (Klass et al., 1998), de ciclos (Chang et al., 2000) e de instrução (Nikolaidis et al., 2005). Um dos principais agentes de consumo de energia em um processador é o software que está sendo executado 
nele, uma vez que é grandemente responsável pela quantidade de chaveamentos de sinais nas unidades funcionais dentro do processador.

Nos últimos anos, FPGAs (Field-Programmable Gate Array) têm apresentado um grande desenvolvimento nos quesitos densidade, velocidade e capacidade de armazenamento. Essas características tornaram possível a construção de sistemas complexos formados por um ou mais processadores, blocos de propriedade intelectual e lógica definida pelo usuário. Sistemas tais como esses são chamados de SoPC (System-on-a-Programmable-Chip).

SoCs baseados em FPGA (ou SoPCs) têm se mostrado como uma excelente opção de implementação para sistemas que necessitam de um alto desempenho. Uma das áreas que se beneficiam de implementações SoC é a robótica móvel, uma vez que os algoritmos envolvidos são computacionalmente complexos. Por exemplo, Bonato et al. (2004) usam soluções System-on-Chip baseadas em FPGA para implementar algoritmos de reconhecimento de gestos. Além dessa, podem-se citar outras aplicações móveis que demandam um grande poder computacional, tais como reconhecimento de voz em tempo real e análise e transmissão de vídeo.

A computação reconfigurável Compton e Hauck (2000b); DeHon e Wawrzynek (1999); Bondalapati e Prasanna (2002), representada neste projeto pelos FPGAs, visa fornecer ao projetista a flexibilidade do software, por meio das linguagens de descrição de hardware, e a velocidade inerente a sistemas contruídos em hardware. A fim de aproveitar o alto potencial de configurabilidade dos dispositivos FPGA, a utilização de processadores soft-core torna-se cada vez mais importante. Processadores soft-core permitem uma personalização detalhada de suas características arquiteturais, possibilitando uma melhor adequação às restrições de tempo e espaço em um projeto. Como exemplo de processadores softcore, podem-se citar o Nios II da Altera (Altera, 2005a), o MicroBlaze da Xilinx (Xilinx, 2006) e o Mico 32 da Lattice (Lattice, 2006).

Da mesma forma como acontece com processadores de propósito geral, um software sendo executado em um processador soft-core também é bastante responsável pelo consumo de energia do dispositivo no qual está presente, no caso, um FPGA (de Holanda et al., 2007). Isto porque cada instrução executada pelo processador ativa e desativa o funcionamento de elementos lógicos, redes de interconexão e bancos de memória dentro do FPGA. 
Um dos modelos de estimação de potência mais utilizados para prever o consumo de energia de um software é o chamado modelo de estimação ao nível de instrução. Basicamente, esse modelo considera a energia total consumida por um programa como sendo a soma da energia consumida por cada uma das suas instruções. Vários autores propuseram variações dessa metodologia tendo como alvos processadores de propósito geral, tais como o ARM e o MIPS (Sinha e Chandrakasan, 2001; Tiwari et al., 1994; Russell e Jacome, 1998; Sami et al., 2000; Lee et al., 2001).

Assim como ocorre em projetos de sistemas embutidos atuais, projetos de sistemas baseados em FPGA também possuem severas restrições a respeito de dissipação de potência e calor, o que torna o estudo de mecanismos de economia de energia cada vez mais importante. Motivado pelas necessidades de controle do consumo de energia desses sistemas e pelo ambiente de prototipação rápida fornecido pelos dispositivos reconfiguráveis aos projetistas de hardware, este projeto de mestrado propõe a construção de um estimador de potência para o processador soft-core Nios II.

O estimador implementado deverá ser futuramente anexado a um ferramenta que está sendo desenvolvida no Laboratório de Computação Reconfigurável (LCR) do Instituto de Ciências Matemáticas e de Computação da USP (ICMC-USP), chamada ARCHITECT+. Ela deverá proporcionar a geração de hardware e software para robôs móveis, integrando computação de alto desempenho e algoritmos de aprendizado de máquina. O objetivo da ferramenta, chamada ARCHITECT + , é fornecer um ambiente para co-projeto de hardware/software em plataformas de FPGAs com aplicação em robótica móvel. A partir de um algoritmo de aplicação em robótica móvel, escrito em linguagem C, o sistema gerará automaticamente um SoC para acelerar a aplicação. Assim, programas gerados pela ferramenta para serem executados no processador Nios II poderão ser avaliados quanto à obediência a possíveis restrições de energia do sistema sendo desenvolvido.

\subsection{Objetivos}

O objetivo principal deste trabalho é construir um estimador de potência para softwares que têm como alvo o processador Nios II da Altera. Mais especificamente, propiciar uma metodologia 
que permita a desenvolvedores de códigos em linguagem C para o processador Nios II, saber de antemão quanta energia será consumida, ou quanta potência será dissipada devido à execução de programas e aplicações de robótica móvel.

\subsection{Organização do Trabalho}

No Capítulo 2 é apresentada a tecnologia de Computação Reconfigurável por meio dos tipos de hardware reconfigurável existentes e os dispositivos de última geração. São descritas as ferramentas EDA da Altera que foram utilizadas neste projeto e a tecnologia do processador Nios II. O Capítulo 3 mostra os principais fatores que afetam o consumo de potência em um FPGA, assim como as ferramentas para estimação de potência disponibilizadas pela Altera para utilização conjunta com suas ferramentas EDA. Mostra ainda alguns dos trabalhos relacionados ao tema de estimação de potência para vários níveis de abstração. O Capítulo 4 descreve a metodologia de estimação de potência adotada para este trabalho, assim como as tarefas de instrumentação eletrônica, configuração de hardware e configuração do software, terminando com uma análise dos resultados obtidos. Por fim, o Capítulo 5 apresenta a conclusão do trabalho e sugestões para trabalhos futuros. 


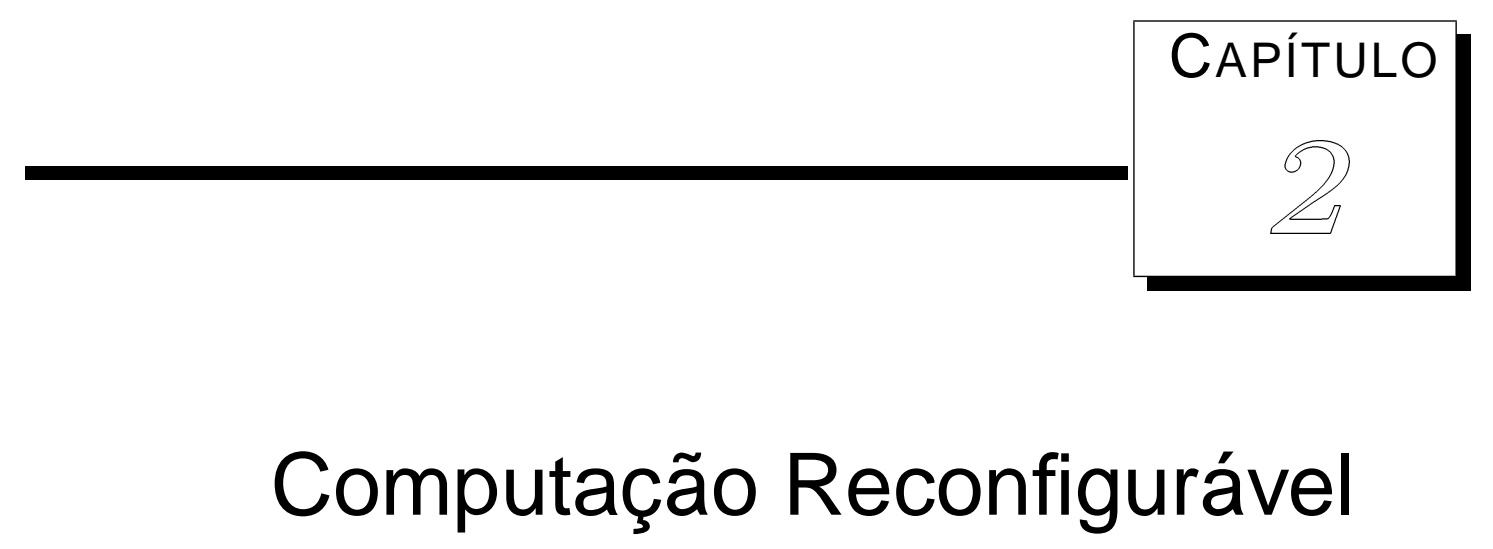

O conceito de computação reconfigurável existe há muito tempo (Estrin et al., 1963) e atualmente o termo refere-se a sistemas que incorporam alguma forma de programabilidade de hardware, ou seja, uma capacidade de adaptação de como o hardware é utilizado mediante o emprego de pontos de controle físico (Compton e Hauck, 2000a). Uma das características mais marcantes da computação reconfigurável, é a de possibilitar a aceleração de aplicações por meio da adaptação do hardware a necessidades computacionais específicas (Bondalapati e Prasanna, 2002). Esta característica, combinada à habilidade de desempenhar computação em hardware para aumentar o desempenho, sem perder muita da flexibilidade de uma solução por software, faz da computação reconfigurável uma ótima alternativa para a construção de SoCs. Neste capítulo, serão vistos os tipos existentes de hardware reconfigurável, com um enfoque maior na tecnologia FPGA, a qual foi utilizada neste trabalho. Também serão descritas algumas ferramentas EDA da Altera, as quais auxiliam na construção de projetos em hardware reconfigurável. Por fim, serão mostradas algumas características do processador embutido Nios II, o qual é o alvo da estimação de potência neste trabalho. 


\subsection{Hardware Reconfigurável}

O surgimento dos circuitos integrados (chips) permitiu a integração de grandes quantidades de transistores dentro de uma mesma pastilha de silício. Em Bondalapati e Prasanna (2002) é apresentado o gráfico da Figura 2.1, que mostra o crescimento do número de transistores por $\mathrm{cm}^{3}$ e a evolução esperada para os próximos anos. Atualmente existem chips como o Cell da IBM que contém 234 milhões de transístores e o Pentium 4 Extreme Edition da Intel, que possui 250 milhões de transístores (Lyons, 2006). Essa evolução permitiu que uma variedade de chips fossem construídos em pastilhas de silício, tais como os apresentados na Figura 2.2

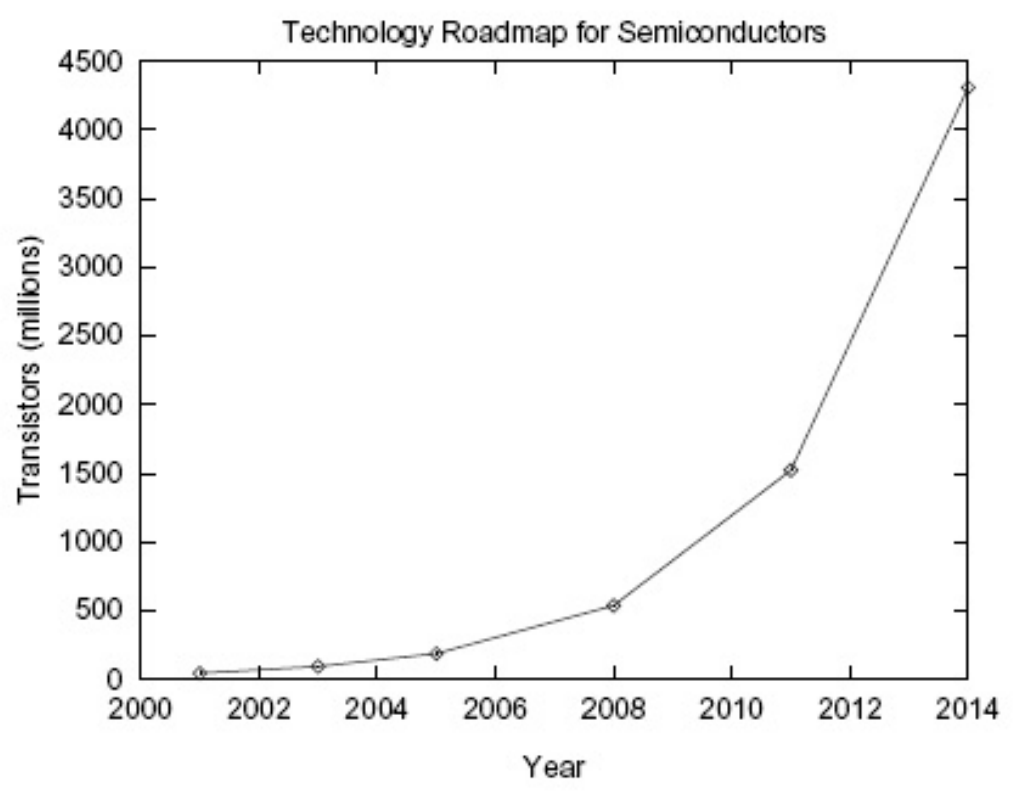

Figura 2.1: Evolução do número de transistores através do tempo

Tradicionalmente, a funcionalidade de cada chip é pré-determinada por seu fabricante. Assim, um usuário que deseja definir a lógica de um circuito elaborado por ele deverá utilizar diversos tipos de chips, o que pode trazer desvantagens ao sistema, tais como: aumento da área necessária para conexão; perda de desempenho devido ao atraso existente nas portas de entrada e saída; e aumento do consumo de energia. A fim de contornar esses problemas, foram criados alguns tipos de circuitos integrados que permitem ao usuário, e não mais ao fabricante, definir a funcionalidade. Dentre eles, podem-se citar:

- VLSI (Very Large Scale Integration) 


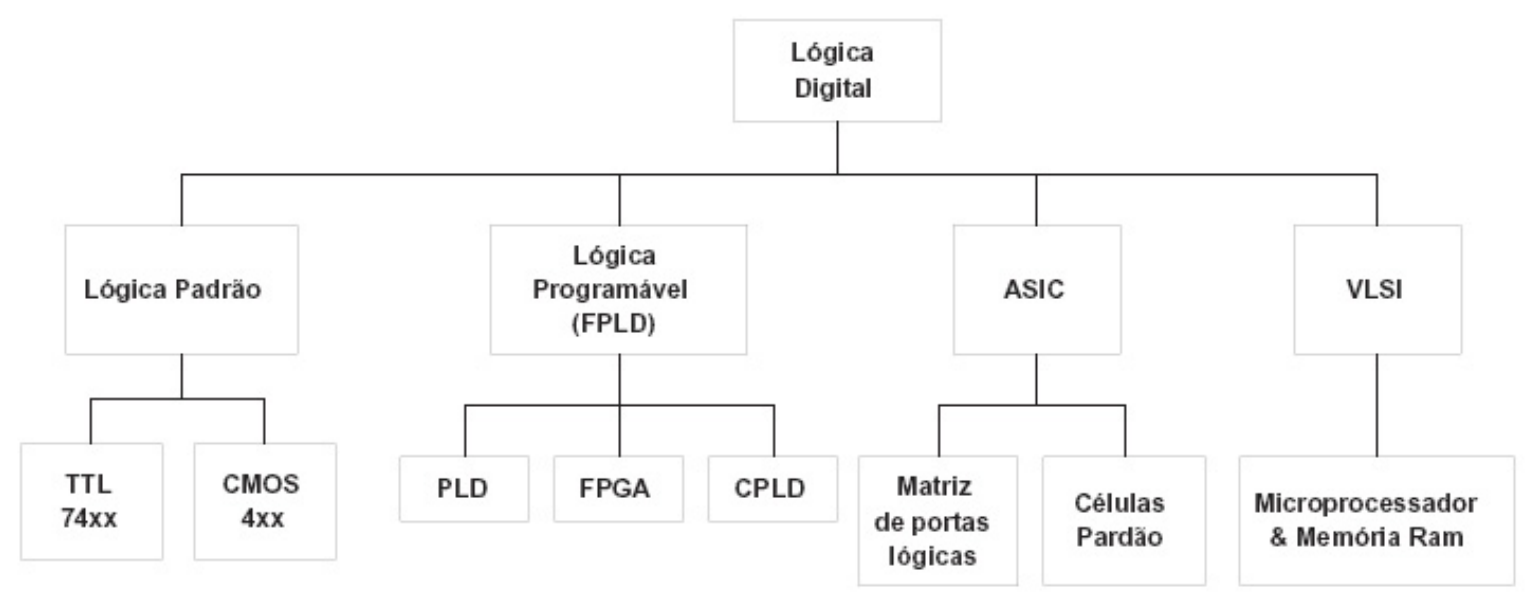

Figura 2.2: Chips disponíveis para implementação de circuitos lógicos (Hamblen e Furman, 2001)

- ASIC (Application Specific Integrated Circuit)

- PLD (Programmable Logic Device)

- CPLD (Complex Programmable Logic Device)

- FPGA (Field-Programmable Gate Array)

No caso dos tipos VLSI e ASIC, a funcionalidade do chip é definida pelo usuário, porém, implementada pelo fabricante. Isto porque a tecnologia empregada no processo de implementação possui um custo muito elevado. Uma das desvantagens da utilização destes chips está no fato de que não é possível realizar atualizações (upgrades) em suas funções. Contudo, eles apresentam qualidades, como baixo consumo de energia, alto desempenho e baixo custo quando produzido em larga escala. Os tipos PLD, FPGA e CPLD permitem ao usuário definir e implementar a funcionalidade do chip. Essa característica permite que tanto o custo de desenvolvimento quanto o tempo para a obtenção do produto sejam inferiores aos do ASIC. Todavia, a utilização desses chips ocasiona um aumento na complexidade e uma queda no desempenho (Hamblen e Furman, 2001). A relação entre as tecnologias mencionadas pode ser vista na Figura 2.3. 


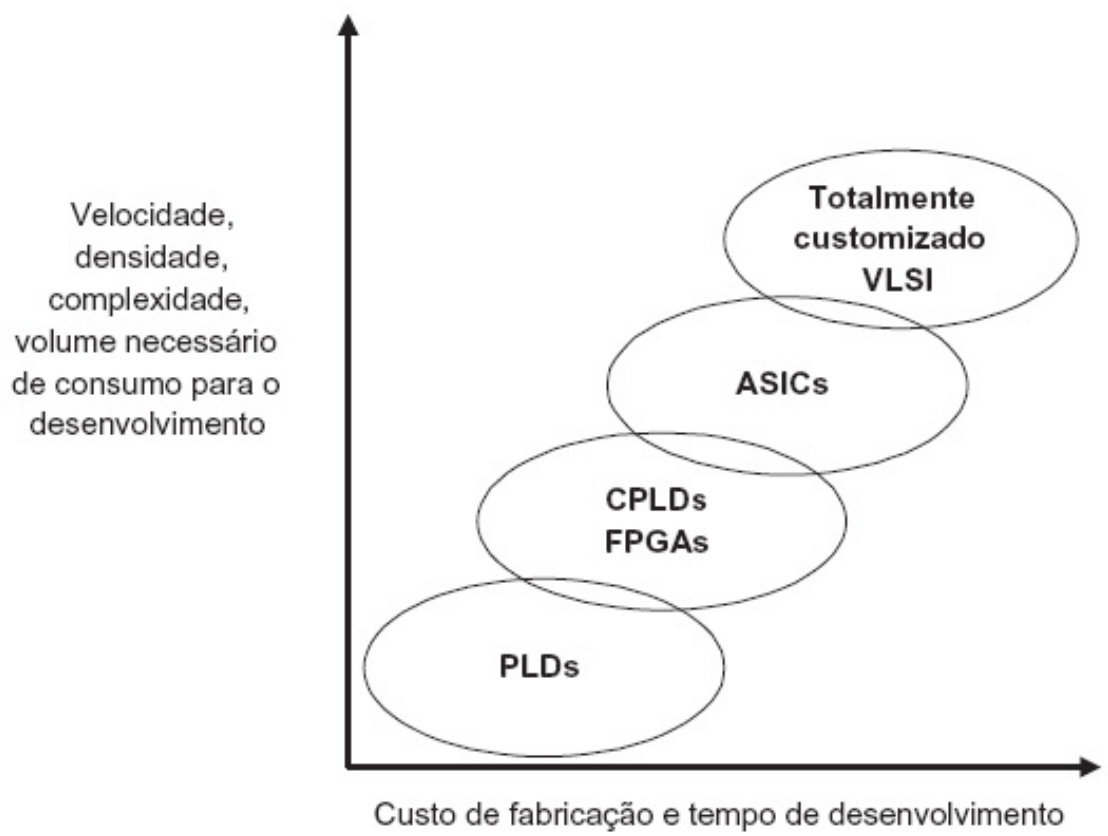

Figura 2.3: Relação entre as diferentes tecnologias de hardware (Hamblen e Furman, 2001)

\subsubsection{FPGAs de última geração}

Atualmente, existem diversos fabricantes de dispositivos FPGA, dentre os quais podemos citar as empresas Altera, Xilinx, Actel, Cypress Semiconductor, QuickLogic e Lattice/Vantis Corporation. As empresas Altera e Xilinx são as que representam a maior parte deste mercado, oferecendo uma grande variedade de dispositivos. Os dispositivos FPGA fornecidos pela empresa Altera são agrupados em famílias conforme suas principais características. As famílias principais são:

- Cyclone: FPGAs de primeira geração que têm como características a baixa densidade e o baixo custo;

- Cyclone II: FPGAs de segunda geração e de baixo custo para projetos que não tenham grande necessidade de desempenho e densidade;

- Stratix: FPGA de propósito geral e com alto desempenho;

- Stratix GX: FPGA de alto desempenho com transceptores (transceivers integrados);

- Stratix II: FPGA de propósito geral com alta densidade e desempenho; 
- Stratix II GX: FGPA com alta densidade, alto desempenho e com transceptores integrados.

- Stratix III: FPGA de terceira geração de alto desempenho e alta densidade, com um grande número de recursos para processamento digital de sinal.

Mediante as características de cada família é possível dividi-las em dois grupos. Um grupo das FPGAs de baixa densidade e baixo desempenho formado pelas famílias Cyclone e Cyclone II. O segundo grupo compreende as FPGAS de alto desempenho e com um um número maior de elementos lógicos (maior densidade), sendo formado pelas famílias Stratix, Stratix GX, Stratix II, Stratix II GX e Stratix III. A Tabela 2.1 mostra a variação no número de elementos lógicos para os FPGAs de cada família da Altera, bem como o número de cores do processador Nios II versão standard que caberiam em cada FPGA (o tamanho do core é de 1400 elementos lógicos).

\begin{tabular}{|c|c|c|}
\hline Família & Elementos Lógicos & $\begin{array}{c}\text { Estimativa no número máximo de } \\
\text { Cores do Nios II/s no FPGA }\end{array}$ \\
\hline \hline Cyclone & 2910 a 20060 & 14 \\
\hline Stratix GX & 10570 a 41250 & 29 \\
\hline Cyclone II & 4608 a 68416 & 48 \\
\hline Stratix & 10570 a 79040 & 56 \\
\hline Stratix II GX & 33880 a 132540 & 94 \\
\hline Stratix II & 15600 a 179400 & 128 \\
\hline Stratix III & 47500 a 338000 & 241 \\
\hline
\end{tabular}

Tabela 2.1: Variação do número de elementos lógicos nos dispositivos de cada família de FPGAs da Altera e estimativa do número máximo de cores do processador Nios II standard no FPGA

Os elementos lógicos apresentados na Tabela 2.1 correspondem aos blocos básicos que constituem os FPGAs, os quais são utilizados pela Altera para determinar o tamanho dos dispositivos. A medida da capacidade dos dispositivos apresentada através de elementos lógicos é considerada mais tangível do que a medida apresentada através de portas lógicas.

As famílias de dispositivos de FPGA da empresa Xilinx também podem ser divididas basicamente em dois grupos. O primeiro seria o Virtex, ideal para sistemas que necessitem de alto desempenho e densidade. O segundo é o Spartan, com FPGAs de baixo custo. A última família de alto desempenho lançada foi a Virtex-5, a qual é subdividida em 3 famílias distintas: LX, LXT e SXT. A LX é adequada para soluções para aplicações lógicas que requerem um 
alto desempenho, a LXT oferece uma solução mais completa que a LX com recursos de baixo consumo de energia, já a SXT é a mais indicada para aplicações de DSP. A Tabela 2.2 mostra a variação do número de células lógicas em cada sub-família da família Virtex-5.

\begin{tabular}{|c|c|}
\hline Sub-família & Células Lógicas \\
\hline \hline Virtex-5 LX & 30720 a 331776 \\
\hline Virtex-5 LXT & 30720 a 331776 \\
\hline Virtex-5 SXT & 34816 a 94208 \\
\hline
\end{tabular}

Tabela 2.2: Variação do número de células lógicas em cada sub-família da família Virtex-5

As células lógicas da Tabela 2.2 correspondem aos blocos básicos dos dispositivos da Xilinx, que servem para indicar a capacidade dos seus FPGAs.

\subsection{Ferramentas EDA}

Durante os anos 50 e 60, os circuitos eram desenhados manualmente em pranchetas. Ao final dos anos 60 e 70, ferramentas CAD (Computer-Aided Design) foram utilizadas para criar esquemáticos e ferramentas CAE (Computer-Aided Engineering) foram usadas para analisar os projetos. Na metade dos anos 80, as ferramentas CAD e CAE para circuitos eletrônicos uniram-se no termo "eletronic design automation". Ferramentas EDA permitem projetar, verificar e simular o desempenho de circuitos eletrônicos em um chip ou em uma placa de circuito impresso. Sem essas ferramentas, o número de dispositivos eletrônicos existentes atualmente no mercado seria muito menor.

Neste trabalho foi utilizada uma ferramenta EDA desenvolvida pela Altera, chamada Quartus II. Essa ferramenta possibilita o desenvolvimento de projetos para uma ampla variedade de famílias de FPGA da Altera. A descrição de um projeto pode ser feita utilizando-se linguagens de programação de hardware, tais como VHDL, Verilog ou $\mathrm{AHDL}^{1}$, além da representação esquemática por meio de blocos ou netlists obtidas com ferramentas de síntese de terceiros. A descrição do projeto deve então passar por uma etapa de compilação presente no Quartus II e que é formada pelos seguintes módulos (Altera, 2005b):

- Análise e Síntese: realiza a síntese lógica com o objetivo de minimizar a lógica do pro-

\footnotetext{
${ }^{1}$ Linguagem da descrição de hardware criada pela Altera
} 
jeto, além de realizar o mapeamento da tecnologia, fazendo com que o projeto use os recursos do dispositivo alvo;

- Fitter: Arranja e roteia a lógica de um projeto em um dispositivo;

- Assembler: Converte as associações realizadas na fase do Fitter em arquivos de programação para o dispositivo;

- Analisador de Temporização: Analisa e valida o desempenho da temporização de toda a lógica em um projeto.

A Figura 2.4 mostra o fluxo padrão de projeto ao utilizar a ferramenta Quartus II.

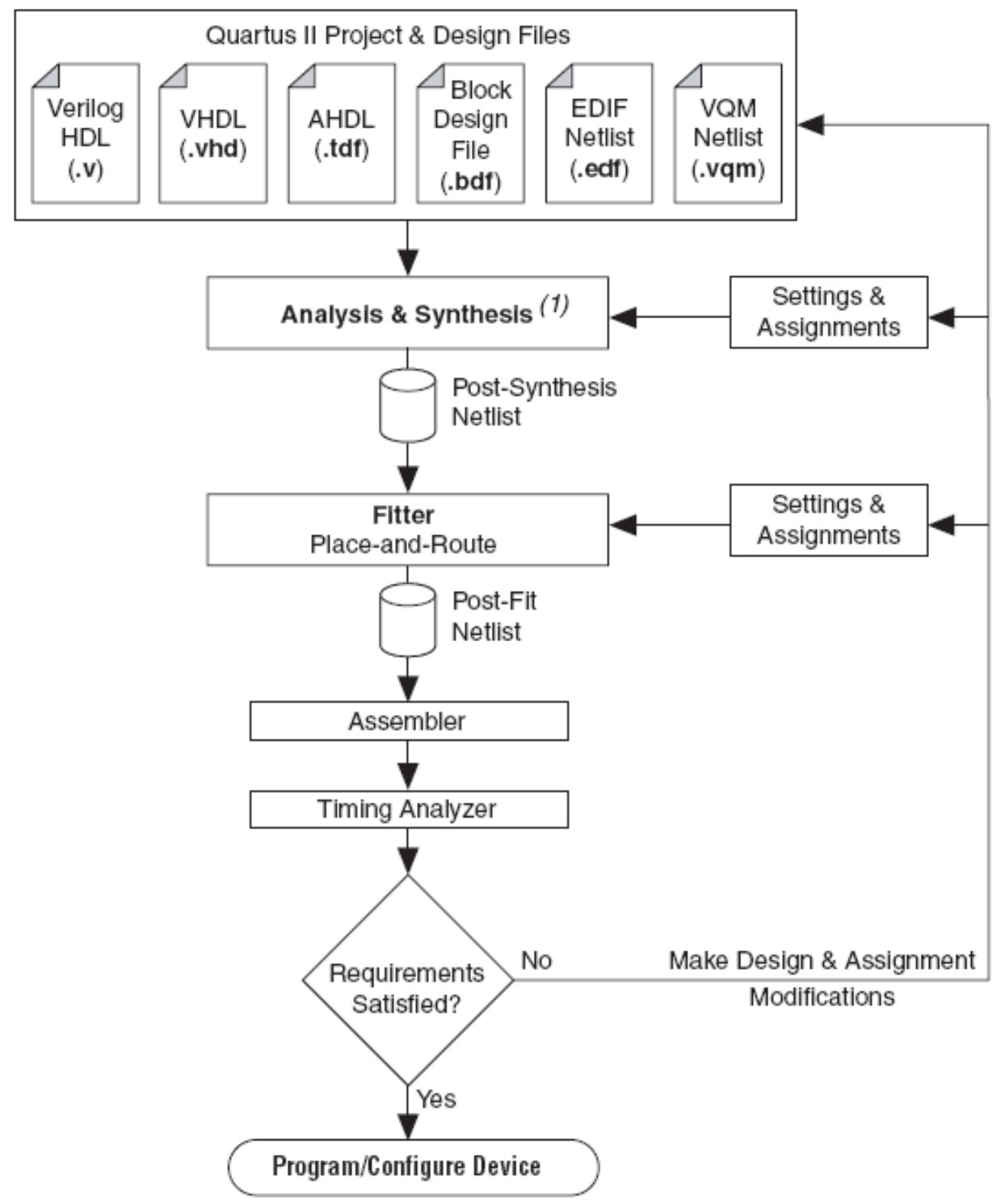

Figura 2.4: Fluxo padrão de projeto para a ferramenta Quartus II (Altera, 2005b) 
Juntamente com o Quartus II, há uma ferramenta, também desenvolvida pela Altera, chamada SOPC Builder (Altera, 2003). Essa ferramenta permite a construção de SoPCs baseados em barramento e formados por processadores, memórias internas, interfaces para memórias externas, periféricos e lógica definida pelo usuário. A utilidade do SOPC Builder para esse projeto está no fato de que a ferramenta permite a composição de sistemas formados por cores do processador Nios II.

O SOPC Builder gera arquivos HDL nos quais estão implementados os módulos formadores do sistema. Esses arquivos são então compilados pelo Quartus II, para que se possa programar o dispositivo alvo com o sistema projetado.

Ambas as ferramentas foram utilizadas neste trabalho com o objetivo de construir um sistema contendo o processador Nios II.

\subsection{Processador Nios II}

Geralmente SoCs em FPGA são formados por um ou mais processadores embutidos, blocos de memória interna, interface para memória externa e lógica definida pelo projetista de hardware. Neste projeto, foi utilizado o processador embutido Nios II, desenvolvido pela Altera (Altera, 2005a). Ele é um processador soft-core, RISC, de propósito geral e que é projetado para atender a uma grande variedade de aplicações embutidas, podendo interagir facilmente com a lógica produzida pelo projetista. A Figura 2.5 mostra o diagrama de blocos do core do processador Nios II.

A família de processadores Nios II é formada por três núcleos: o Fast (Nios II/f), o Economic (Nios II/e) e o Standard (Nios II/s). Cada um deles são otimizados para classes específicas de preço e desempenho, embora tenham o mesmo conjunto de instruções (ISA ${ }^{2}$ ) de 32 bits. Um sistema composto pelo processador Nios II é equivalente a um microcontrolador ou a um “computador em um chip", o qual inclui uma CPU e uma combinação de periféricos e memória em um único chip. O termo "sistema do processador Nios II" refere-se a um núcleo do Nios II, um conjunto de periféricos on-chip, memória on-chip e interfaces para memórias off-chip, todos implementados em um único chip da Altera.

\footnotetext{
${ }^{2}$ Instruction Set Architecture
} 


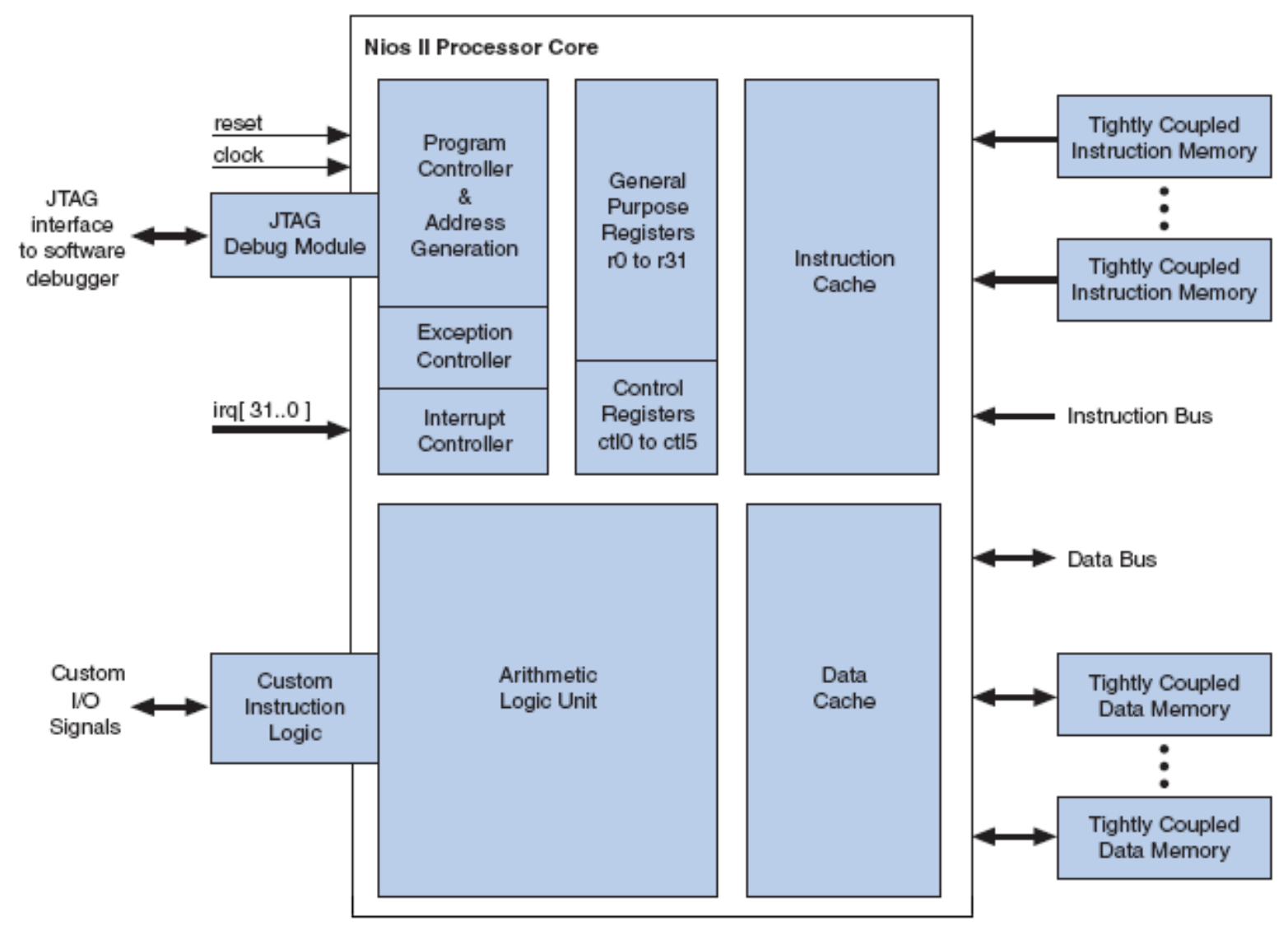

Figura 2.5: Diagrama de blocos do core do processador Nios II (Altera, 2005a)

Neste trabalho são utilizados dois núcleos diferentes do Nios II: o Economic e o Standard. A diferença principal entre esses núcleos está no fato de que o primeiro não possui pipeline e nem memória cache. O segundo, em sua configuração padrão, possui 5 estágios de pipeline e 4KB de memória cache.

\subsubsection{Conjunto de Instruções}

O processador Nios II possui 94 instruções de propósito geral dividas em 7 categorias (Duarte, 2006):

- Instruções de transferência de dados: são as instruções de transferência de dados entre memória e registradores (load/store). Existem instruções específicas para lidar com dados de 8,16 e 32 bits com e sem sinal.

- Operações aritméticas e lógicas: implementam operações como adição, subtração, multiplicação, divisão e and, or, xor e nor. 
- Instruções de movimentação: provêm movimentação de dados entre registradores.

- Instruções de comparação: implementam todas as operações relacionais e de equivalência.

- Instruções de deslocamento e rotação: implementam deslocamento e rotação de bits.

- Instruções de controle: implementam instruções de desvio incondicional e chamada de sub-rotinas, desvio de execução em caso de exceções, além de instruções de manipulação de informações da CPU. Implementam ainda instruções de desvio condicional que comparam diretamente valores entre registradores e desviam para o endereço provido se a condição for verdadeira. Estas instruções também permitem as comparações de equivalência e relação.

- Instrução no operation: implementa a instrução no-operation (NOP).

Além das instruções de propósito geral, o Nios II oferece suporte às instruções customizadas. As instruções customizadas são instruções com lógica definível pelo programador. Este pode integrar um circuito lógico ao processador e associá-lo a uma instrução customizada específica. Da mesma forma que as outras instruções do processador, as instruções customizadas possuem dois registradores de entrada e um de saída. O formato da instrução customizada permite criar até 256 instruções diferentes. 


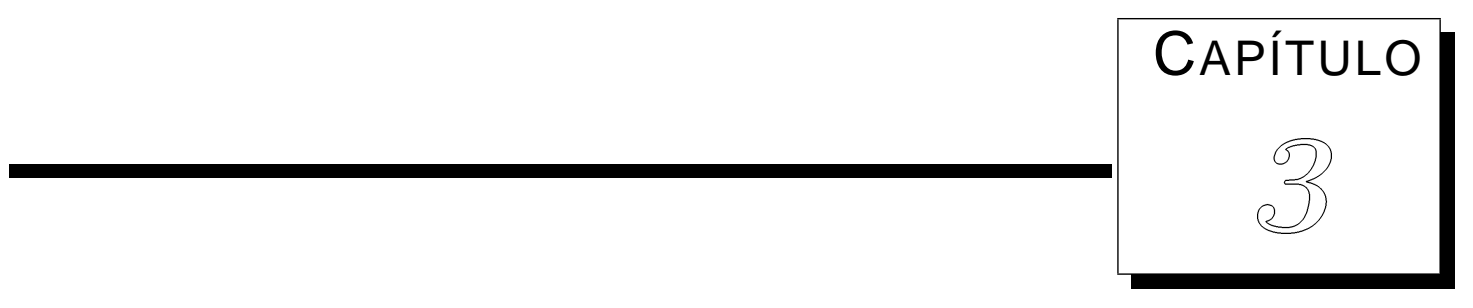

\section{Estimação e Dissipação de Potência}

Inicialmente, este capítulo mostra os diversos fatores envolvidos na dissipação de potência em um dispositivo FPGA. Em seguida, são mostradas algumas pesquisas realizadas na área de estimação de potência. Com a finalidade de mostrar diferentes abordagens para a questão do consumo de energia em sistemas, é dada uma breve descrição de três ferramentas específicas que utilizam modelos de estimação em níveis distintos. Logo após, é feita uma revisão dos trabalhos já realizados sobre estimação de potência, com uma ênfase em modelos de estimação em nível de instrução.

\subsection{Dissipação de potência em FPGAs}

Para que um FPGA funcione apropriadamente é necessária a existência de uma fonte de potência externa. Essa fonte deve fornecer energia elétrica suficiente para que, tanto as operações internas quanto as externas ao dispositivo, sejam executadas com sucesso. Assim, o projeto de tal fonte deve ser feito de maneira a considerar qual será a potência total requerida pelo sistema, bem como quanto dessa potência será dissipada dentro e fora do dispositivo.

A potência total dissipada por um FPGA e pelo sistema no qual ele se encontra é constituída 
por três componentes principais:

- Potência Estática

- Potência Dinâmica

- Potência de E/S

A potência estática é aquela dissipada pelo dipositivo quando este está em standby, ou seja, sem as atividades (chaveamentos) dos sinais. O consumo do dispositivo nesse caso, ocorre devido à dispersão das correntes elétricas. O valor dessa dispersão varia de acordo com o tamanho, a temperatura e o processo de fabricação do FPGA. A potência estática de um FPGA está diretamente relacionada à temperatura do chip, como pode ser visto na Figura 3.1. A fim de obter uma baixa dissipação de potência estática, é necessário manter a temperatura do FPGA no menor valor possível, ainda que seja necessária a utilização de sistemas de refrigeração ou dissipadores de calor.

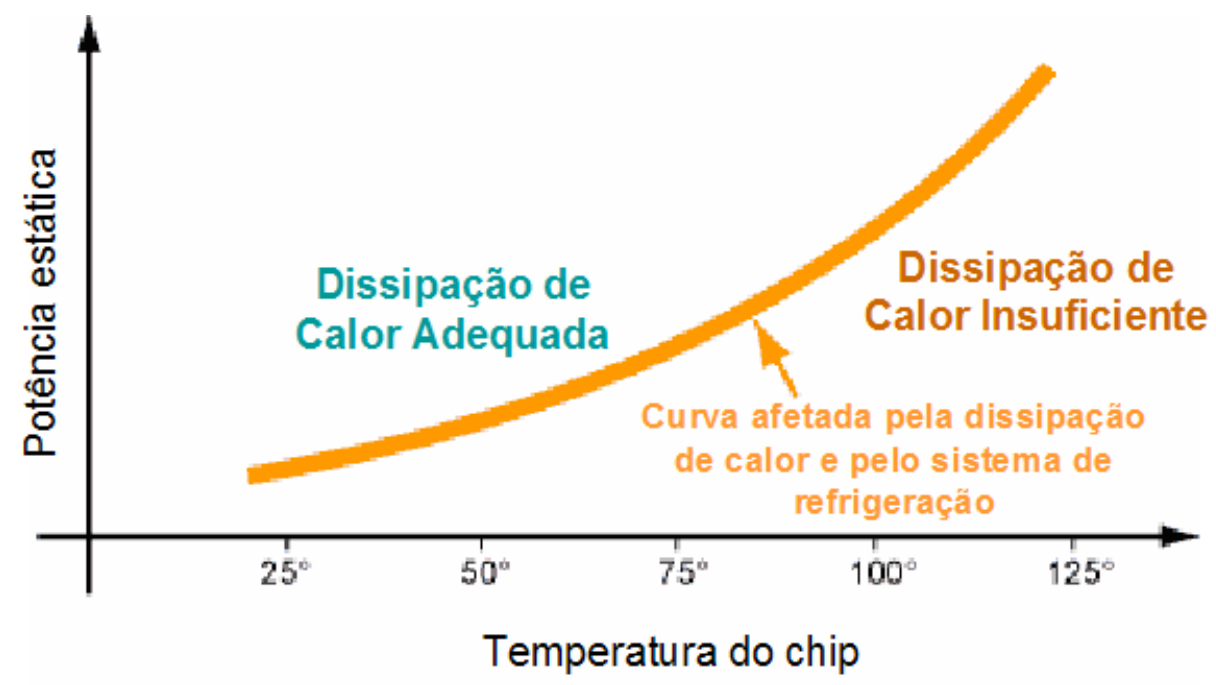

Temperatura mais baixa $=$ Potência mais baixa

Figura 3.1: Relacionamento entre a potência estática e a temperatura do FPGA

A potência dinâmica é dissipada pelas mudanças de níveis lógicos nos nós internos ao FPGA. Esse consumo de energia ocorre devido a carga e a descarga tanto das capacitâncias dos arranjos lógicos quanto das redes de interconexão. Por exemplo, quando um sinal muda seu nível lógico de 1 para 0 , uma certa quantidade de potência é dissipada. Os recursos do FPGA 
que têm uma maior influência sobre o gasto de potência dinâmica em um projeto são os elementos lógicos e os elementos de roteamento utilizados. Além deles, alguns recursos arquiteturais também podem ter uma grande contribuição no consumo, tais como:

- Blocos de memória RAM

- Blocos multiplicadores DSP

- PLLs (Phase Locked Loops)

- Clocks

Assim, o cálculo da potência dinâmica total deverá levar em conta a corrente elétrica utilizada por cada um desses recursos e a voltagem fornecida ao FPGA. A fórmula para o cálculo da potência dinâmica (PD) seria:

$$
P D=V_{C C I N T} \times \sum I_{C C I N T}(E L, R A M, D S P, P L L, \text { Clocks, Roteamento })
$$

A potência de E/S é representada pela potência dissipada devido a carga e a descarga de capacitores externos conectados aos pinos de saída do dispositivo, aos circuitos acionadores operando em modos resistivos, e a qualquer rede externa de terminação.

\subsubsection{Fatores que afetam a dissipação de potência}

Vários fatores interferem na dissipação de potência em um FPGA. Dentre eles estão: a família do dispositivo escolhido para implementação do projeto; fatores ambientais como temperatura do ambiente; fluxo de ar; e refrigeradores e dissipadores de calor. Esta seção descreve brevemente como cada um desses fatores influencia na dissipação de potência.

\section{Seleção do dispositivo}

Empresas como a Altera e a Xilinx, produzem diferentes famílias de FPGAs, cada uma delas com características distintas, tanto de utilização como de dissipação de potência. Esta última 
característica é influenciada diretamente por parâmetros como a tecnologia do processo de fabricação, a voltagem fornecida, o projeto elétrico e a arquitetura do dispositivo. Por exemplo, algumas famílias de FPGA da Altera, como a Cyclone II, dissipam menos potência do que famílias projetadas para sistemas de alto desempenho, como a Stratix II. Além disso, a dissipação de potência pode variar dentro da mesma família. Devido ao maior número de transístores, FPGAs maiores dissipam mais potência estática do que dispositivos pequenos.

Outro fator que contribui para a dissipação de potência é o encapsulamento do FPGA escolhido, pois influencia diretamente na capacidade do dispositivo em dissipar o calor. Dependendo do encapsulamento escolhido e da aplicação do projeto, sistemas de refrigeração fazem-se necessários a fim de manter o chip em seus limites operacionais de temperatura.

Finalmente, o último fator do dispositivo que interfere na dissipação de potência é a variação do processo de fabricação (em FPGAs mais novos, há processos de 65nm). Este fator influencia, principalmente, a dissipação de potência estática, uma vez que o sub-limiar de dispersão de corrente varia exponencialmente com o limiar de voltagem do transístor. A potência dinâmica é pouco afetada por este fator.

\section{Condições do ambiente}

Alguns fatores do ambiente no qual o FPGA se encontra podem influenciar nna dissipação de potência. Quanto maior a temperatura operacional do dispositivo, maior será a dissipação de potência estática. Para diminuir ou mesmo prevenir o aumento da temperatura, sistemas de fluxo de ar e de dissipação de calor podem estar presentes, bem como uma temperatura ambiente apropriada.

O fluxo de ar diz quão rápido o ar aquecido é retirado da superfície do dispositivo e substituído por ar à temperatura ambiente. Essa medida pode ser especificada tanto quanto "ar imóvel", quando não há a utilização de ventiladores, ou como pela capacidade do ventilador em retirar o ar quente. Por exemplo, a Tabela 3.1 mostra a resistência térmica para dispositivos EP1S10 da família de FPGAs Stratix, nos casos de ar imóvel e com fluxo de ar (em pés/min.). Quanto maior o fluxo de ar, menor a resistência térmica do chip com o ambiente. 


\begin{tabular}{|c|c|c|c|c|c|}
\hline Dispositivo & Pinos & $\begin{array}{c}\theta_{J C}\left({ }^{\circ} \mathrm{C} / W\right) \\
\mathbf{A r} \text { imóvel }\end{array}$ & $\begin{array}{c}\theta_{J C}\left({ }^{\circ} \mathrm{C} / W\right) \\
100 \text { pés/min }\end{array}$ & $\begin{array}{c}\theta_{J C}\left({ }^{\circ} \mathrm{C} / W\right) \\
200 \text { pés/min }\end{array}$ & $\begin{array}{c}\theta_{J C}\left({ }^{\circ} \mathrm{C} / W\right) \\
400 \text { pés/min }\end{array}$ \\
\hline \hline \multirow{3}{*}{ Stratix } & 484 & 11,9 & 9,8 & 8,4 & 7,2 \\
\cline { 2 - 6 } EP1S10 & 672 & 16,8 & 13,7 & 11,9 & 10,5 \\
\cline { 2 - 6 } & 672 & 17,2 & 14 & 12,2 & 10,8 \\
\cline { 2 - 6 } & 780 & 10,9 & 8,8 & 7,4 & 6,3 \\
\hline
\end{tabular}

Tabela 3.1: Resistência térmica em dispositivos EP1S10 da família Stratix, da Altera

Outro recurso utilizado para diminuir a temperatura de um FPGA é a utilização de dissipadores de calor. Um dissipador de calor permite uma melhor transferência de calor do dispositivo para o ambiente em redor devido à uma maior superfície exposta ao ar. Quanto maior a capacidade de dissipar o calor, menor será a resistência térmica.

\section{Recursos do Projeto}

Pinos de saída dissipam potência dinâmica devido às cargas necessárias para acionar componentes off-chip. Alguns padrões de E/S requerem resistores externos que geralmente dissipam potência constante (estática) do pino de saída.

Como já mencionado na Seção 3.1, elementos lógicos e arquiteturais têm uma forte influência sobre a dissipação de potência dinâmica. Assim, um projeto com um número maior de elementos lógicos, elementos multiplicadores e blocos de memória tende a dissipar mais potência do que um projeto com um número pequeno de tais elementos. Além disso, o modo de operação de cada um desses elementos de circuito afeta o consumo de energia. Por exemplo, um bloco DSP realizando multiplicações de tamanho $18 \times 18$ e um bloco DSP realizando operações de "multiplica-acumula" dissipam quantidades diferentes de potência dinâmica. Isto porque há diferentes quantidades de capacitância interna sendo carregadas em cada transição. A potência estática também é afetada pelo modo de operação de um elemento de circuito, ainda que em um grau muito pequeno.

Redes de sinais globais estendem-se por grandes porções do dispositivo e possuem um alta capacitância, resultando em uma dissipação de potência dinâmica significativa. O tipo do sinal global também é importante. Por exemplo, dispositivos como os da família Stratix II, suportam vários tipos de redes globais de clock que se estendem por todo o dispositivo ou por apenas um pequena porção do dispositivo. Redes de clock que se estendem por menores regiões possuem 
uma capacitância mais baixa e, dessa forma, tendem a dissipar menos potência. Além disso, a localização dos blocos de arranjo lógico (LABs - Logic Array Blocks) que são acionados pela rede de clock pode também ter um impacto no consumo de energia, uma vez que o software Quartus II desabilita automaticamente ramos inúteis de clock.

\section{Atividade dos sinais}

Um fator de grande importância para a estimação da dissipação de potência é o comportamento de cada sinal presente no projeto. Há duas estatísticas essenciais para essa estimação: a taxa de chaveamento e a probabilidade estática.

A taxa de chaveamento de um sinal é dada pela média das vezes em que ele muda seu valor por unidade de tempo. Essa taxa é importante pois, quando ocorre a transição de um sinal, há uma carga (ou descarga) na capacitância de alguns elementos lógicos, o que causa a dissipação de potência. As unidade para taxa de chaveamento são transições por segundo, sendo que uma transição é a mudança do nível lógico 1 para o 0 ou do 0 para 1.

A probabilidade estática de um sinal é a fração de tempo em que um sinal está logicamente em 1 durante o período operacional do dispositivo que está sendo analisado. A probabilidade estática varia de 0 (sempre em ground) a 1 (sempre logicamente alto).

A potência dinâmica aumenta linearmente com a taxa de chaveamento, conforme a carga capacitiva é carregada mais frequentemente para a lógica e para o roteamento. A potência estática dissipada tanto pela lógica quanto pelo roteamento pode, as vezes, ser afetada pelas probabilidades estáticas de seus sinais de entrada (Altera, 2005b).

\subsubsection{Ferramentas de Análise e Estimação de Potência}

Com o crescimento da complexidade dos projetos em FPGA, a necessidade de se conhecer as informações sobre potência em um projeto tem se tornado cada vez mais importante. Em um projeto de um PCB (Printed Circuit Board), a potência dissipada pelo dispositivo precisa ser estimada de forma precisa, a fim de possibilitar o desenvolvimento de soluções de potência apropriadas, como fontes de potência, reguladores de voltagem, dissipadores de calor e sistemas de refrigeração. Para isto é necessária a existência de ferramentas que permitam obter estimação 
durante a fase de desenvolvimento do projeto.

A Altera provê um conjunto de ferramentas chamadas PowerPlay Power Analyzer e PowerPlay Early Power Estimator que permitem fazer a estimação de potência de projetos desenvolvidos para FPGAs da própria Altera. Como pode ser visto na Figura 3.2, a ferramenta Early Power Estimator pode ser utilizada nas fases iniciais do projeto, quando este ainda está sendo concebido. O preço dessa estimação inicial é a menor precisão dos resultados. A ferramenta Power Analyzer deve ser utilizada após as etapas de síntese, arranjo e roteamento, quando há dados mais concretos sobre a estrutura e o comportamento do projeto. Essa ferramenta é capaz de fornecer uma estimação mais precisa do que a dada pelo Early Power Estimator.

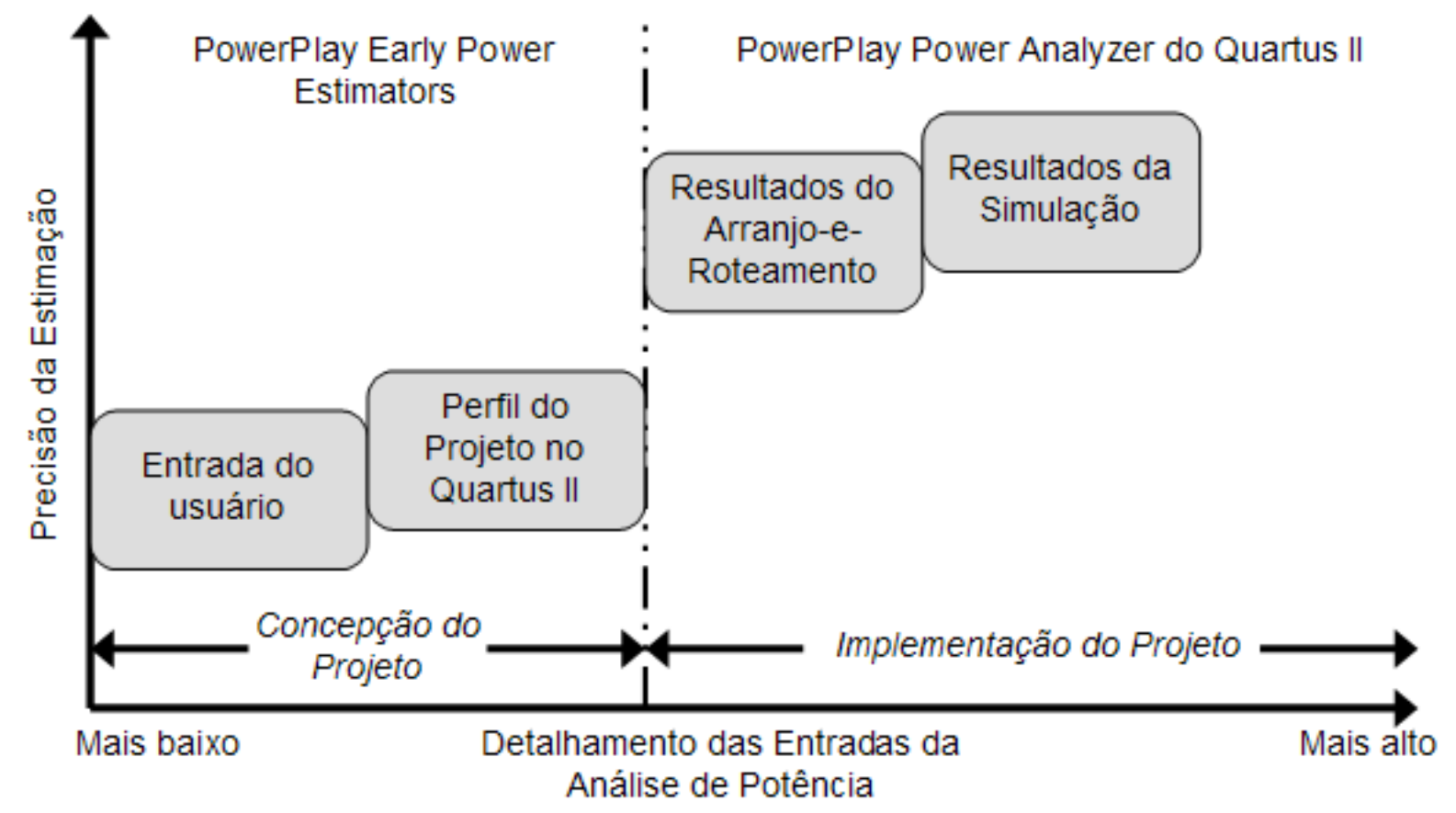

Figura 3.2: Precisão da estimação, em relação as fases do projeto

A Tabela 3.2 mostra as diferenças entre as ferramentas referente as fases de desenvolvimento em que cada uma pode ser utilizada, aos requisitos, à precisão, às entradas e às saídas de dados.

\section{PowerPlay Power Analyzer}

A ferramenta PowerPlay Power Analyzer é uma ferramenta para estimação de potência que vem acoplada ao software Quartus II. Mediante uma série de entradas e após as etapas de síntese e fitting em um dispositivo alvo, é possível obter uma estimativa bastante precisa do consumo de 
Tabela 3.2: Comparação entre as ferramentas PowerPlay Early Power Estimator e PowerPlay Power Analyzer

\begin{tabular}{|c|c|c|}
\hline Característica & Early Power Estimator & Power Analyzer \\
\hline Fase no ciclo de projeto & A qualquer hora & Depois do fitting (ajustamento) \\
\hline Requisitos de ferramenta & Programa de Planilhas/Quartus II & Quartus II \\
\hline Precisão & Média & Média a alta \\
\hline Entrada de dados & $\begin{array}{l}\text { - Utilização de recursos } \\
\text { - Requisitos de clock } \\
\text { - Condições do ambiente } \\
\text { - Taxa de chaveamento }\end{array}$ & $\begin{array}{l}\text { - Projeto após o fitting } \\
\text { - Requisitos de clock } \\
\text { - Resultados da } \\
\text { simulação RTL } \\
\text { - Resultados da } \\
\text { simulação pós-fitting } \\
\text { - Atividades dos sinais por } \\
\text { nó ou entidade } \\
\text { - Valores padrão da } \\
\text { atividade dos sinais } \\
\text { - Condições do ambiente }\end{array}$ \\
\hline Saída de dados & $\begin{array}{l}\text { - Dissipação total de potência } \\
\text { térmica } \\
\text { - Potência estática térmica } \\
\text { - Potência dinâmica térmica } \\
\text { - Dissipação de potência off-chip }\end{array}$ & $\begin{array}{l}\text { - Potência térmica total } \\
\text { - Potência estática térmica } \\
\text { - Potência dinâmica térmica } \\
\text { - Potência térmica por } \\
\text { hierarquia de projeto } \\
\text { - Potência térmica por } \\
\text { tipo de bloco } \\
\text { - Dissipação de potência off-chip }\end{array}$ \\
\hline
\end{tabular}


potência de um projeto. Isto acontece porque o Power Analyzer já conhece tanto o dispositivo alvo quanto como o projeto está arranjado e roteado dentro do dispositivo.

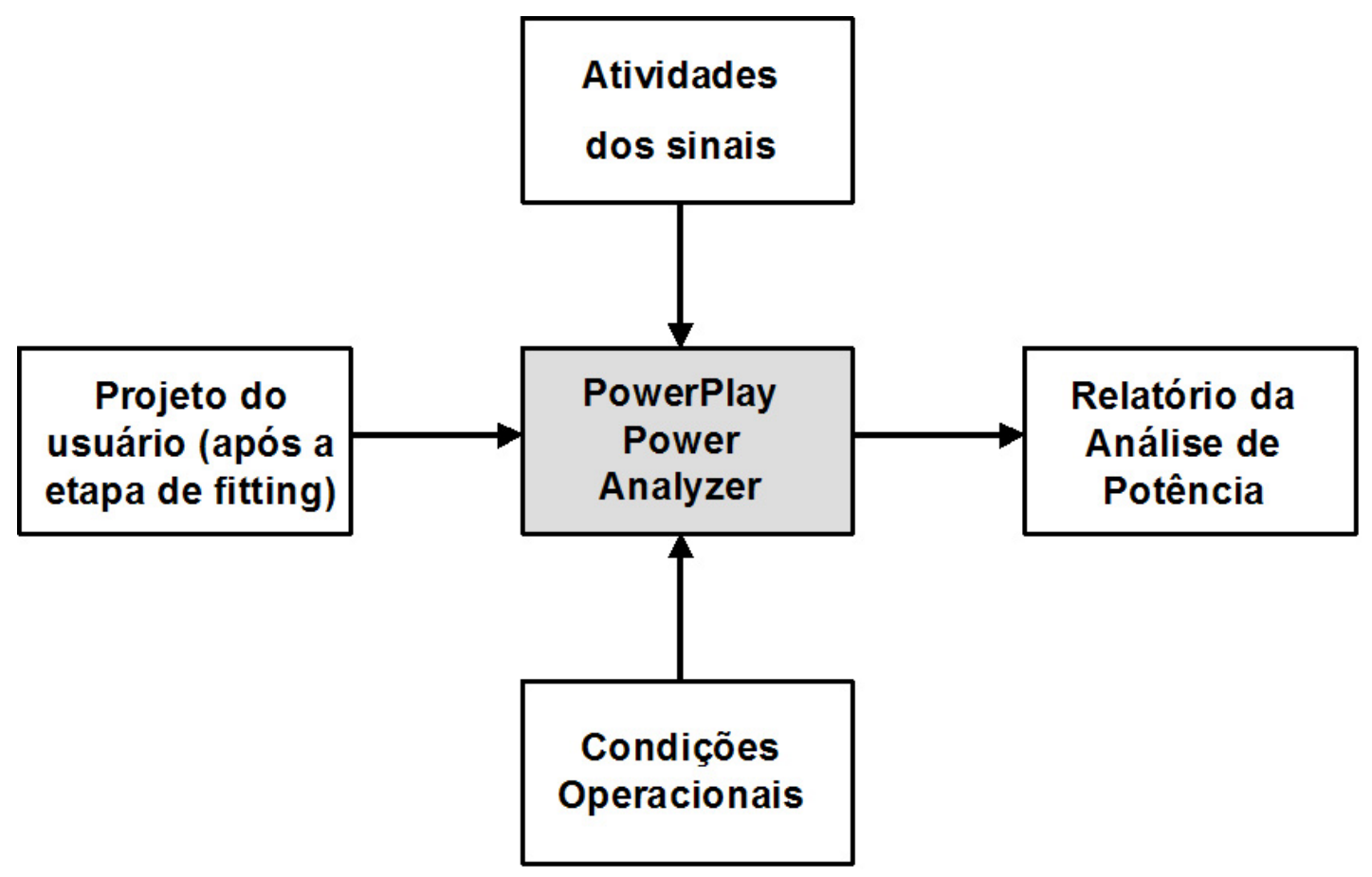

Figura 3.3: Fluxo de projeto com otimização de energia da ferramenta PowerPlay

O fluxo da ferramenta apresentado na Figura 3.3 mostra as classes de entrada necessárias para a realização da estimação de potência. Para algumas famílias de FPGA, como a Cyclone II e a Stratix II, podem-se especificar condições operacionais do projeto, tais como:

- Características de potência do dispositivo

- Condições do ambiente e temperatura do chip (junção)

- Modelagem térmica da placa

Outra necessidade do Power Analyzer para realizar uma estimação precisa é uma fonte de dados sobre as atividades dos sinais. As seguintes fontes podem ser utilizadas para fornecer dados sobre a atividade dos sinais:

- Resultados de simulações

- Atribuições dos nós, das entidades e do clock fornecidos pelo usuário

- Atribuição da taxa de chaveamento padrão fornecida pelo usuário 
- Estimação com ausência de vetor (quando o usuário não apresenta ao estimador simulações ou dados sobre as atividades dos sinais, são utilizadas técnicas estatísticas para estimar essas atividades)

\section{PowerPlay Early Power Estimator}

O PowerPlay Early Power Estimator é uma ferramenta para estimação de potência criada pela Altera e que consiste em uma planilha do tipo Microsoft Excel, dividida em seções de acordo com a característica arquitetural do dispositivo escolhido para o projeto. Algumas seções gerais apresentadas pelo Early Power Estimator são:

- Sinais de clock: a ferramenta deve possuir informações sobre o clock utilizado no projeto uma vez que sinais globais influenciam no consumo de potência

- Elementos lógicos: informação importante pois quanto maior o número de elementos lógicos maior o consumo de potência

- Blocos de processamento de sinal digital: a utilização de blocos DSP interfere no consumo de potência dinâmica devido a cargas e descargas durante as transições realizadas para efetuar multiplicações.

- PLLs: Phase-Locked Loops são componentes que geram um sinal de saída de clock baseado em um sinal de entrada de clock e geralmente são utilizados para multiplicar a freqüência de clocks. Assim, PLLs influenciam diretamente no consumo de potência devido aos constantes chaveamentos de seus sinais.

- Blocos de memória RAM: informações como o tipo de memória RAM (M512, M4K e MRAM) e o tamanho dos dados devem ser fornecidos à ferramenta de estimação.

- Informações de potência de E/S: devido a alta carga necessária para realizar operações de E/S, informações desse tipos devem ser fornecidas à ferramenta para uma boa estimação.

Para uma melhor compreensão, a Figura 3.4 mostra a planilha do PowerPlay Early Power Estimator. 


\subsection{ESTIMADORES DE POTENNCIA}

Essa ferramenta tem a vantagem de poder ser utilizada mesmo que o projeto ainda não esteja iniciado, ou esteja em sua fase inicial. Neste caso, o projetista deve fornecer os dados manualmente à planilha do Early Power Estimator. Contudo, inserir os dados manualmente pode consumir um bom tempo, além da precisão da estimação ficar fortemente dependente da qualidade dos dados fornecidos pelo projetista.

Para projetos parcialmente completos, a ferramenta Quartus II é capaz de gerar um arquivo de estimação que serve como entrada de dados para a planilha. Ainda assim, alguns valores devem ser editados manualmente a fim de que os recursos do dispositivo descritos na planilha reflitam fielmente aqueles utilizados no projeto. Isso elimina grande parte do tempo gasto para preencher manualmente a planilha. Contudo, a precisão da estimação ainda está dependente da qualidade dos dados sobre recursos do dispositivo fornecidos pelo projetista.

\subsubsection{Considerações}

Um item importante a ser observado com relação às ferramentas PowerPlay Power Analyzer e PowerPlay Early Power Estimator é que elas não levam em consideração o código fonte em C a ser executado no Nios II. Estas duas ferramentas apenas estimam a dissipação de potência do hardware colocado dentro do FPGA. As ferramentas apresentadas não conseguem, por exemplo, prever se uma dada instrução contida em um programa em $\mathrm{C}$ que utiliza instruções para processamento de sinal digital, como por exemplo a GAXPY (de Holanda et al., 2006) será executada um milhão de vezes, o que pode comprometer a precisão da estimação da dissipação de potência.

\subsection{Estimadores de Potência}

O objetivo desta seção é mostrar metodologias e ferramentas que estão relacionadas a este trabalho de mestrado. Assim, primeiramente, serão descritos diferentes modelos de ferramentas capazes de realizar estimação de potência de sistemas embutidos em diferentes níveis (nível de software, nível de arquitetura de hardware e nível de lógica de hardware)(Hodjat, 2001). Esses modelos serão representados pelas ferramentas JouleTrack (MIT), SimplePower (Penn State 
University) e PACT (Northwestern University). Em seguida serão apresentados outros modelos e ferramentas de estimação de potência em nível de software, uma vez que este é o nível de atuação do estimador desenvolvido neste trabalho.

\subsubsection{JouleTrack}

JouleTrack é uma ferramenta web capaz de traçar o perfil de energia de um código fonte em C. Ela funciona para os microprocessadores StrongARM SA-1100 e Hitachi SH-4. A estimação de potência realizada por essa ferramenta é feita em nível de instrução e é capaz de calcular o consumo de energia para um dado software com 3\% de precisão. Deve-se observar que neste caso o cálculo do consumo de energia do microprocessador acontece quando este está executando o código do programa.

A ferramenta necessita de alguns dados de entrada para realizar a estimação, tais como as condições operacionais (por exemplo, a freqüência do processador), otimizações de compilação (como tamanho de memória ou desempenho) e mapeamentos de memória. Basicamente, o resultado gerado pela ferramenta é baseado no perfil de energia traçado em nível de intrução para os microprocessadores. Os perfis de energia do software são encontrados medindo-se a corrente consumida pelo processador diretamente na fonte de voltagem e calculando-se o consumo de potência de cada instrução enquanto esta é repetida em um loop infinito. Tal procedimento é realizado para diferentes freqüências de operação nos dois processadores.

Esse experimento nos processadores StrongARM SA-110 e Hitachi SH-4 mostra que a variação do consumo de corrente é bem pequeno. Assim, como uma estimação de primeira ordem, considera-se que o consumo de corrente de um pedaço de código é independente do código e depende somente da voltagem operacional e da freqüência do processador. A Figura 3.5 mostra o consumo de corrente de diferentes benchmarks para diferentes níveis de freqüência de operação do processador StrongARM. A variação máxima do consumo de corrente é menor que $8 \%$.

JouleTrack também propõe níveis de estimação de energia de segunda e terceira ordem. O modelo de segunda ordem utiliza classes/ciclos de instrução para uma melhor modelagem da estimação de energia. Por esse modelo, o erro de predição foi reduzido a menos de $2 \%$. O 


\subsection{ESTIMADORES DE POTÊNCIA}

modelo de terceira ordem utiliza uma metodologia para separar os componentes de dispersão e chaveamento, apresentando menos do que $6 \%$ de erro. Detalhes técnicos e equações são explicados melhor em Sinha e Chandrakasan (2001).

Ao utilizar a ferramenta JouleTrack, o usuário fornece o código em linguagem C, o qual é compilado e linkeditado (linked) com qualquer biblioteca $\mathrm{C}$ padrão. O usuário também pode especificar argumentos de linha de comando que o programa pode precisar. Não havendo erros, o programa é então executado em um simulador ARM que produz as saídas do programa, a listagem em assembly e estatísticas de tempo de execução como o próprio tempo de execução, a contagem de ciclos, etc. São essas estatísticas que alimentam o "motor" de estimação, o qual por sua vez calcula o perfil de energia. O diagrama de blocos dessa ferramenta é apresentada na Figura 3.6.

\subsubsection{SimplePower}

SimplePower é um framework utilizado para avaliar a influência de fatores como compilação, arquitetura e algoritmos de alto nível sobre o consumo de energia. SimplePower é uma ferramenta de estimação em nível de transferência de registradores, a qual é baseada em uma arquitetura com pipeline de cinco estágios. A arquitetura do conjunto de instruções é um subconjunto do conjunto de instruções do SimpleScaler, o qual é uma suíte de ferramentas capazes de simular microprocessadores e que estão disponíveis publicamente (Hodjat, 2001). Os cinco estágios do pipeline são: IF (instruction fetch ou busca de instruções), ID (instruction decode ou decodificação de instruções), EXE (execução), MEM (acesso a memória) e WB (write back). Os principais componentes do SimplePower são o seu core, a interface de estimação de potência RTL, as tabelas de capacitância de chaveamento dependentes de tecnologia, o simulador de cache/barramento e o carregador (loader). A cada ciclo de clock, o core do SimplePower simula a execução de todas as instruções ativas e invoca as interfaces de estimação de potência correspondentes para todas as unidades funcionais ativadas. A ferramenta contém a interface de estimação de potência RTL, a qual consiste em um conjunto de rotinas em C e foi desenvolvida para todas as unidades funcionais em nível arquitetural de modo a manter a independência de tecnologia do simulador. As tabelas de capacitância de chaveamento dependentes de 
tecnologia também foram desenvolvidas para as diferentes unidades funcionais, tais como somadores, ULA, multiplicadores, shifters, controladores, arquivo de registradores, registradores de pipeline e multiplexadores. O simulador de cache simula o status da cache de instruções e de dados. O simulador de barramento "espiona" o barramento de endereço e de dados da cache de instruções e o barramento de endereço e de dados da cache de dados. Ele grava o número total de acessos e o número de transições nesses barramentos. A Figura 3.7 mostra o framework da ferramenta de estimação de energia.

Essa ferramenta avalia a energia do sistema considerando-o como um todo e não como a soma de partes. Além disso, ela suporta concorrentemente tanto experimentos do compilador quanto da arquitetura. No SimplePower, o código fonte em C é compilado por uma versão do gcc específica do SimpleScaler, o qual gera códigos assembly também do SimpleScaler. O assembler gas e o carregador/linkeditor (loader/linker) gld produzem executáveis para o SimplePower, os quais podem ser carregados na memória principal e executados pelo SimplePower. A ferramenta fornece o status final do arquivo de registradores, o número total de ciclos em execução, o número de transições em barramentos on-chip, estatísticas de capacitância de chaveamento para cada estágio do pipeline, estatísticas de capacitência de chaveamento para diferentes unidades funcionais e a capacitância de chaveamento total.

\subsubsection{PACT}

PACT (Power-Aware Architecture and Compilation Techniques) é uma pesquisa desenvolvida pelo departamento de engenharia elétrica e de computação da Northwastern University. O projeto visa desenvolver novas técnicas de minimização do consumo de energia de sistemas computacionais. É a primeira abordagem para entender a necessidade de se considerar o consumo de potência ao tomar decisões arquiteturais (Hodjat, 2001). O objetivo do PACT é receber uma aplicação escrita em linguagem de programação C e gerar código eficiente tanto em potência quanto em desempenho para sistemas de computação embutidos utilizando técnicas arquiteturais power-aware. Como mostrado na Figura 3.8, esse projeto consiste de três tarefas principais e inter-relacionadas. São elas:

- Tarefa A - Técnicas Arquiteturais Power-Aware: Nesta tarefa são aplicadas as técnicas 
power-aware para um processador de propósito geral embutido e um sistema de memória.

- Tarefa B - Técnicas de Compilação Power-Aware: Nesta tarefa é aplicado um compilador C utilizando o framework gcc, o qual realiza uma compilação power-aware e considera a potência como uma métrica de otimização adicional.

- Tarefa C - Ferramentas CAD Power-Aware para Estimação de Potência: Nesta tarefa são desenvolvidas pesquisas na área de estimação de potência em nível comportamental.

\subsubsection{Outros Trabalhos Relacionados}

As abordagens utilizadas para estimação de potência dissipada pelo software baseiam-se ou na realização de uma simulação funcional do processador, ou em medições diretas de energia. Em métodos baseados em simulação, a energia consumida pelo software que está sendo executado é estimada calculando-se o consumo de energia de vários componentes no processador-alvo, por meio de simulações em diferentes níveis.

Mehta et al. (1996) propõem um profiler de potência que grava informações a respeito dos estados anteriores e atuais das unidades funcionais, assim como da capacitâncias de chaveamento correlatas. Como uma extensão a essa abordagem, Chen et al. (1998) apresentam uma técnica capaz de estimar dados sobre o consumo de energia em nível de ciclo, a qual é baseada na decomposição hierárquica das características arquiteturais do processador alvo. Uma forma mais generalizada de um simulador de energia em nível de transferência de registradores, chamado SimplePower é proposto em Ye et al. (2000). Ao invés de concentrar a modelagem na arquitetura alvo, Klass et al. (1998) analisam o efeito da execução seqüencial de diferentes instruções usando uma ferramenta de análise em nível de porta lógica. Uma desvantagem desses modelos de energia baseados em simulação está no fato de que eles não fornecem um mecanismo que possa calcular o consumo de energia do software diretamente da seqüência de instruções.

Por outro lado, em abordagens baseadas em medições, o consumo de energia de um software é caracterizado examinando-se os dados obtidos do próprio hardware. A vantagem dessa abordagem é que o modelo de energia resultante é próximo do comportamento real do proces- 
sador, pois os dados são obtidos diretamente do hardware. Tiwari et al. (1994) descrevem uma técnica para modelagem do custo de energia de um software baseado na corrente média consumida pelo processador alvo. Nessa abordagem, o modelo de energia é dado por uma tabela de custo de potência que armazena o custo básico de cada instrução e dos efeitos inter-instruções. O custo básico para uma instrução é definido como a corrente média consumida por essa instrução sendo executada repetidamente em um laço, multiplicado pelo número de ciclos que cada instância da instrução leva para ser executada. O efeito inter-instrução é definido como o custo adicional de potência que incorre devido à execução seqüencial de diferentes instruções. Contudo, armazenar este efeito inter-instrução aumenta significativamente o tamanho da tabela de custos de potência, requerendo um espaço $O\left(N^{2}\right)$, em que $N$ é o número de instruções do processador. Para corrigir esse problema, uma técnica para agrupar as instruções em classes comuns é proposta em Lee et al. (1997).

Em contraste às abordagens baseadas na corrente média, Russell e Jacome (1998) apresentam um modelo de estimação de energia para software baseado na medição instantânea feita por um osciloscópio digitalizador. Uma técnica mais refinada para obter o consumo de energia é proposta por Chang et al. (2000), onde é medido o consumo de energia em nível de ciclo utilizando-se um hardware de medição desenvolvido na pesquisa. Eles também analisam o impacto de várias propriedades das instruções no consumo de energia baseado em medições. Utilizando essa abordagem, é mostrado que o consumo de energia de um software depende das propriedades das instruções, tais como número de registradores, operandos imediatos, etc..

A fim de explicar o complexo comportamento de energia dos processadores, técnicas de análise estatística são empregadas na estimação de energia de software. Gebotys et al. (2000) e Gebotys e Gebotys (1998) propõem um técnica de estimação e otimização de energia para processadores VLIW, incorporando um método estatístico para analisar padrões de utilização de unidades funcionais das instruções. Essa abordagem tenta predizer o consumo de energia do software utilizando análise de regressão ${ }^{1}$. A predição é utilizada para minimizar o consumo de energia em relação à corrente média consumida. Lee et al. (2001) combinam análise de regressão com métodos empíricos, a fim de encontrar equações de consumo de energia e construir

\footnotetext{
${ }^{1}$ Técnica para quantificar a relação estatística entre duas ou mais variáveis. Serve para testar hipóteses e problemas de predição.
} 
seu modelo de estimação de potência. Esse modelo considera o processador como uma "caixa preta", permitindo sua utilização para diferentes processadores alvo. Estudos feitos por Brandolese et al. (2000) e Sami et al. (2000) apresentam técnicas para estimar o consumo de energia de software utilizando-se uma combinação de decomposição funcional e técnicas de análise estatística. Essas abordagens estão focadas em modelar o consumo de energia em termos de utilização de várias unidades funcionais, objetivando principalmente processadores VLIW. 


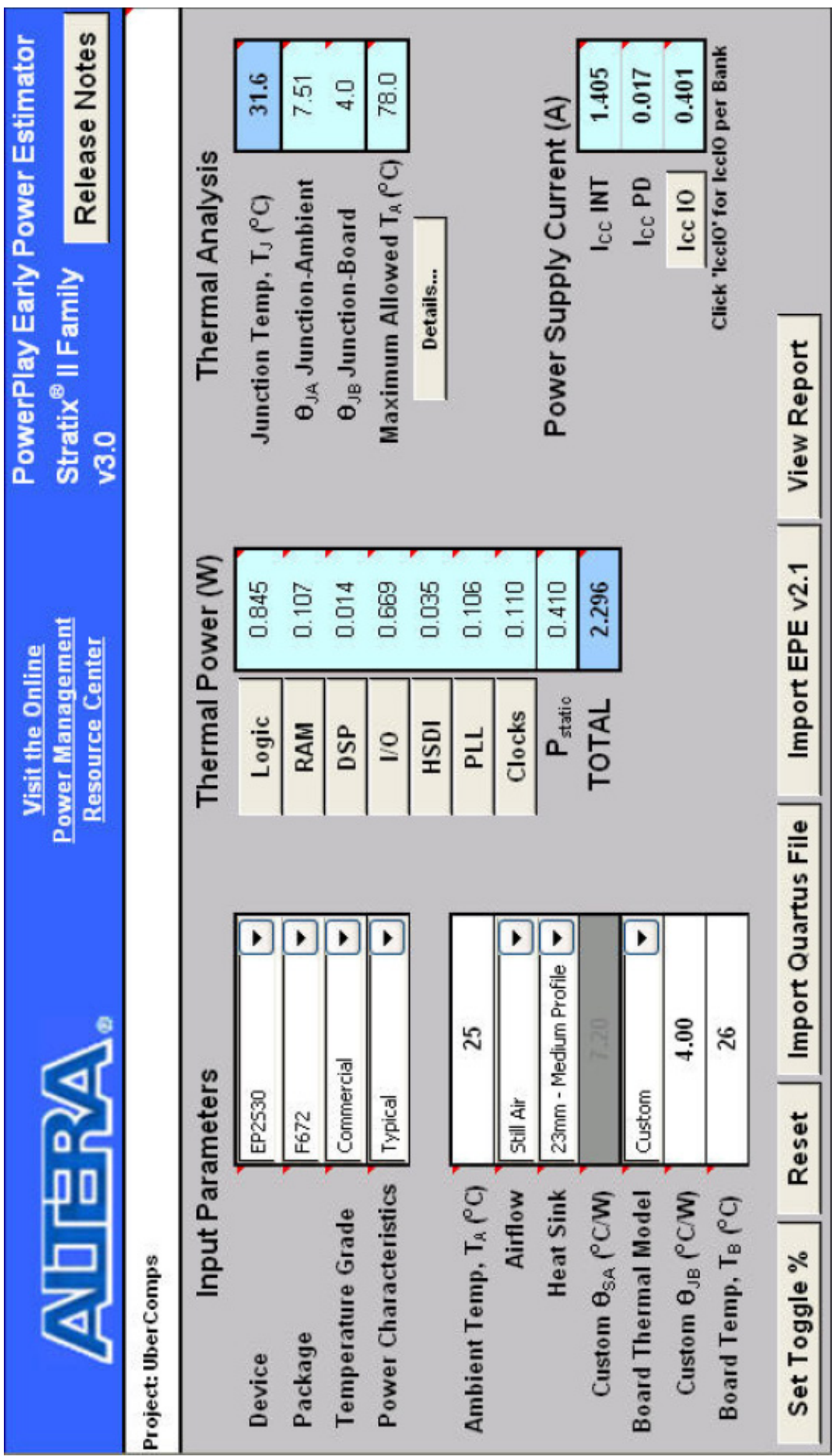

Figura 3.4: Planilha do PowerPlay Early Power Estimator 


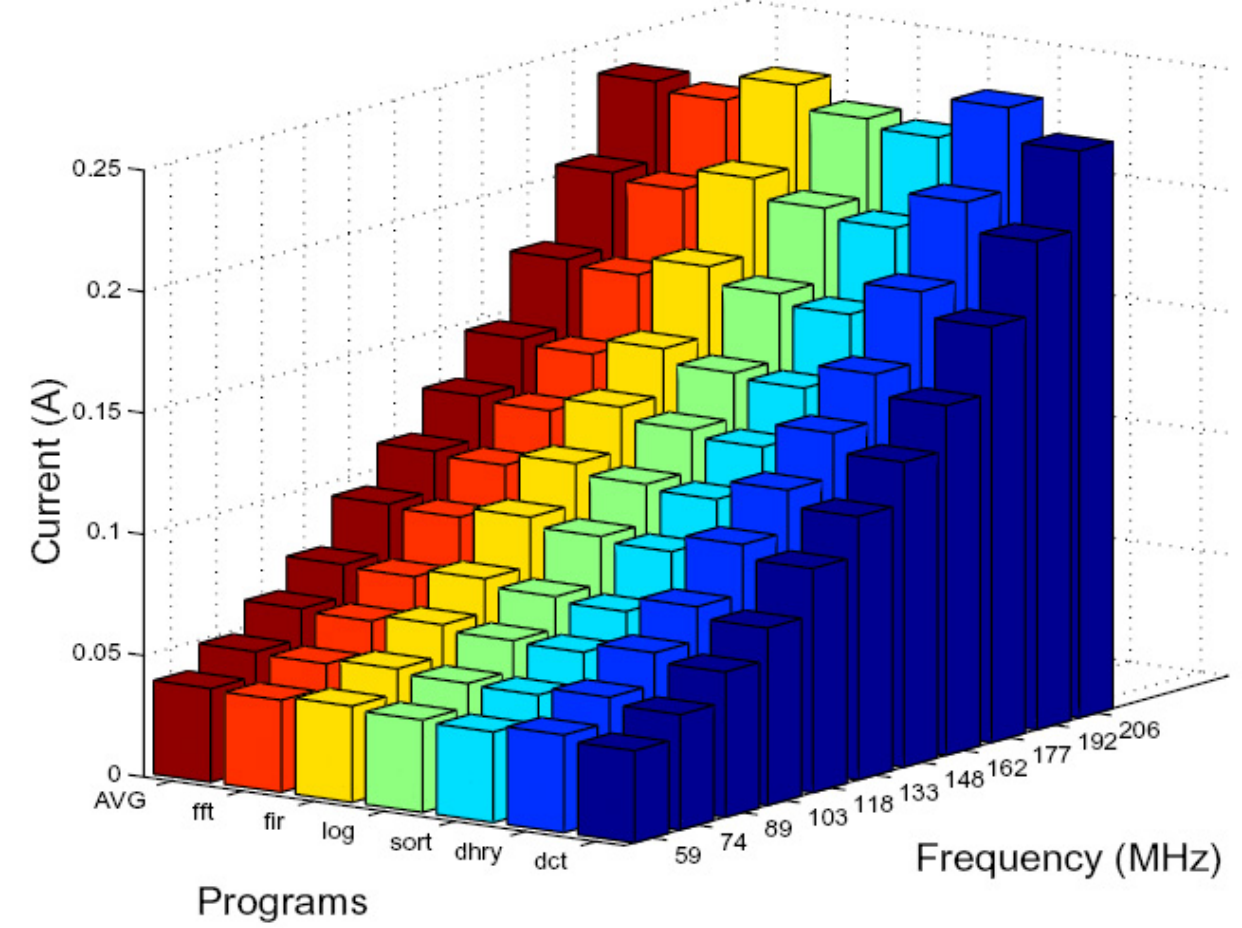

Figura 3.5: Consumo de corrente para benchmarks sendo executados no processador StrongARM a diferentes freqüências de operação

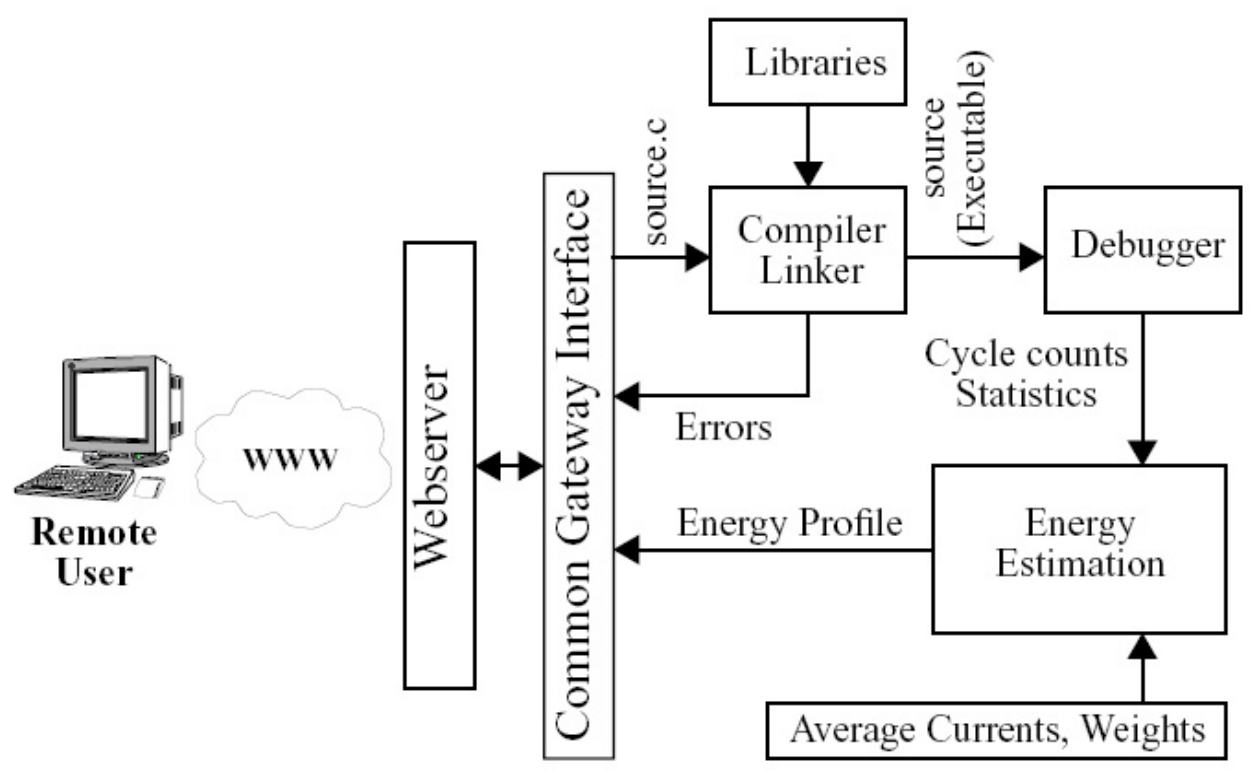

Figura 3.6: Diagrama de blocos da ferramenta JouleTrack 


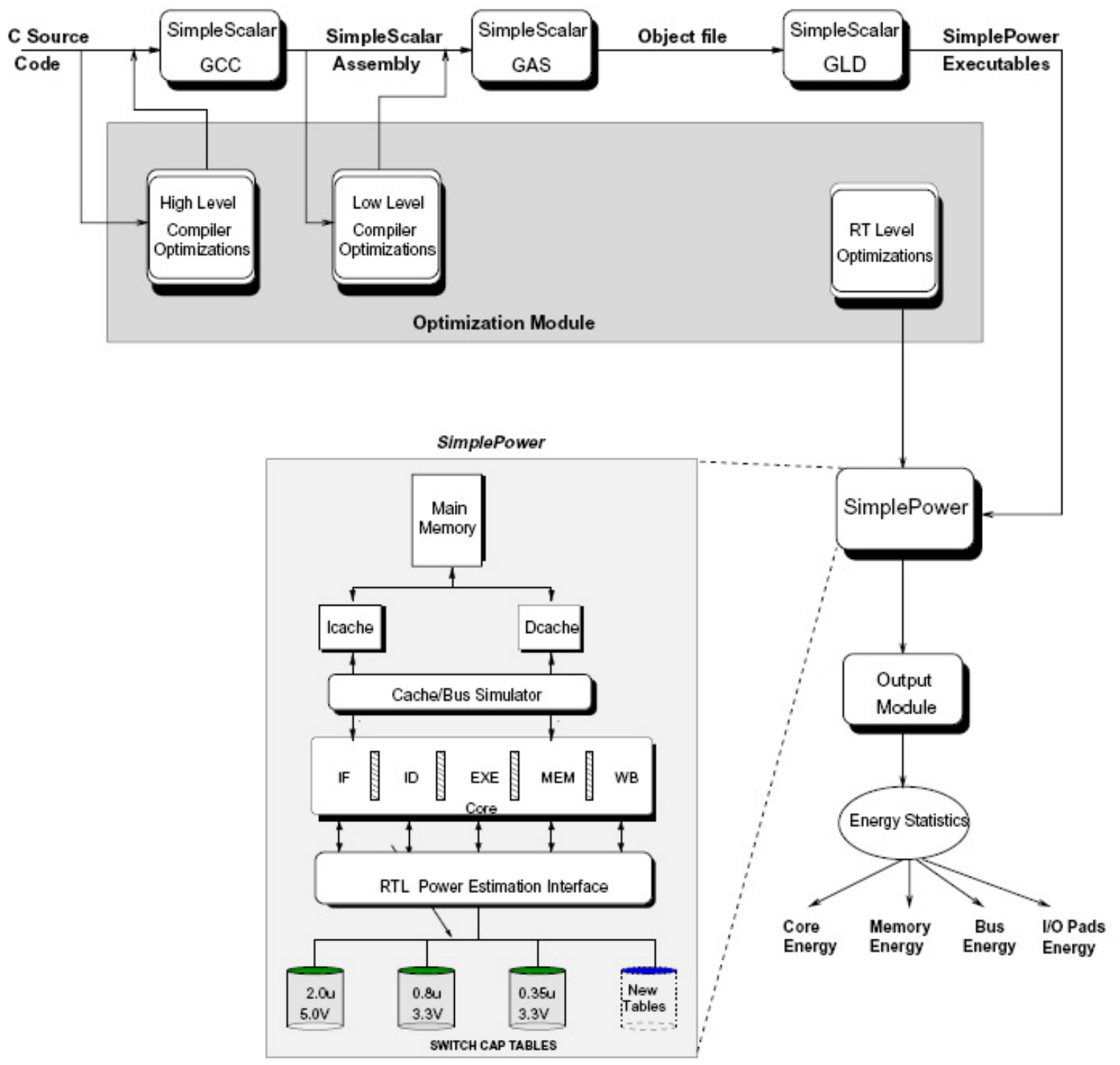

Figura 3.7: Framework de estimação de energia SimplePower 


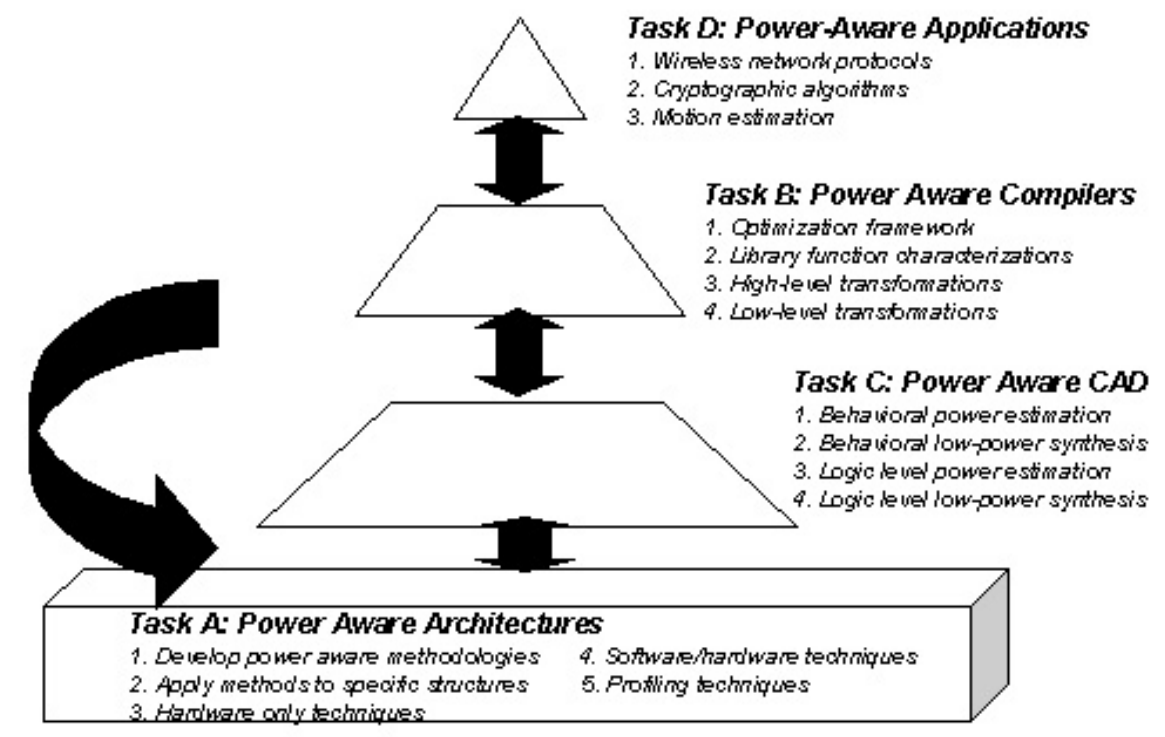

Figura 3.8: Inter-realação entre as tarefas do PACT 



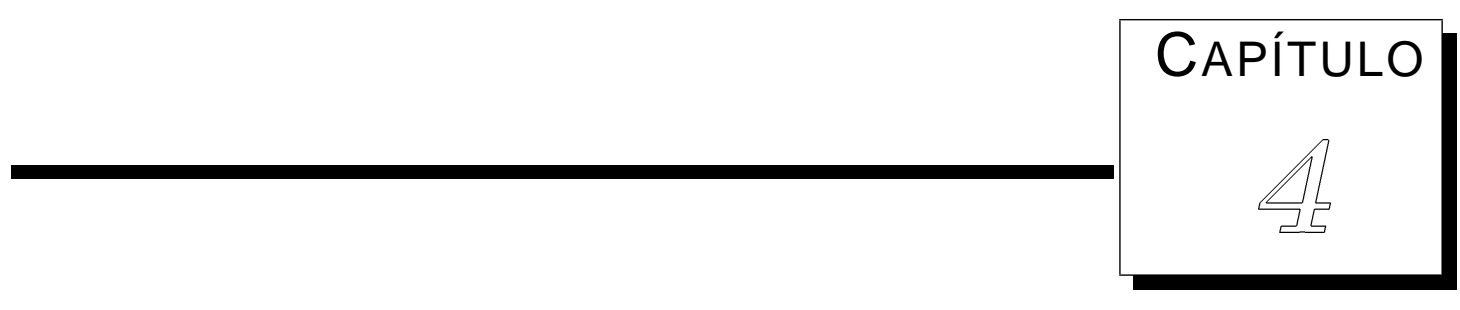

\section{Implementação e Resultados}

Este capítulo descreve os principais detalhes da implementação do estimador de potência proposto por este trabalho de mestrado, desde as etapas de instrumentação do hardware até o modelo final de estimação. São discutidos também os resultados obtidos a partir das medições e suas implicações práticas.

\subsection{Metodologia}

A metodologia para estimação de potência adotada neste trabalho de mestrado é baseada no modelo de estimação em nível de instrução, proposto primeiramente por Tiwari et al. (1994). A idéia principal desse modelo diz que é possível obter a maior parte das informações necessárias para avaliar o custo de consumo de um programa, medindo-se a corrente consumida pelo processador alvo quando este executa repetidamente certas instruções ou seqüências curtas de instruções. Assim, considera-se que toda a complexidade interna de um microprocessador atual esteja "escondida" atrás do seu conjunto de instruções.

Cada vez que uma instrução é executada, ela ativa diferentes unidades funcionais do processador, resultando em atividades de sinais no circuito. Deste modo, é possível associar a cada 
instrução um custo base, o qual representa a corrente consumida por essa atividade. Logo, a estimativa da energia consumida por um programa pode ser calculada com base nos custos de cada uma de suas instruções.

Por meio da equação 4.1, é possível obter o valor da energia, $E$, consumida por um processador durante a execução de um programa (Russell e Jacome, 1998).

$$
E=\int_{t_{0}}^{t_{0}+T} P(t) d t
$$

na qual $T$ é o tempo de execução do software e $P(t)$ é a potência instantânea. Como a potência média, $P_{m e d}$, é definida pela equação 4.2 , a energia $E$ pode ser representada conforme a equação 4.3.

$$
\begin{gathered}
P_{\text {med }}=\frac{1}{T} \int_{t_{0}}^{t_{0}+T} P(t) d t \\
E=P_{\text {med }} \times T
\end{gathered}
$$

O tempo $T$ está diretamente relacionado ao número de ciclos, $N$, de execução do software e ao período do clock, $\tau$, do processador, ou seja $T=N \times \tau$.

A potência média, $P_{m e d}$, pode também ser calculada como o produto da corrente média consumida durante a execução do programa, $I_{m e d}$, com a voltagem fornecida pela fonte de alimentação, $V_{c c}$ (equação 4.4).

$$
P_{\text {med }}=I_{\text {med }} \times V_{c c}
$$

A idéia por trás do modelo de estimação em nível de instrução possibilita o cálculo da corrente média, $I_{m e d}$, em função do custo base de cada instrução assembly presente no programa sendo executado.

Durante a execução de um programa, algumas instruções podem ser utilizadas um número maior vezes do que outras. Assim, dependendo do número de ocorrências no código assembly e do fluxo de execução do programa, cada instrução pode ter uma influência maior ou menor 
no consumo médio de corrente. Conseqüentemente, o cálculo da corrente média deve levar em consideração não somente quais instruções compõem um programa, mas também quantos ciclos de clock são gastos por cada uma delas. A equação 4.5 mostra o cálculo da corrente média consumida por um programa, considerando esses fatores.

$$
I_{m e d}=\frac{1}{N} \sum_{k} I_{k} N_{k}
$$

na qual, $I_{k}$ representa a corrente consumida pela instrução $k$ e $N_{k}$, o número de ciclos de execução utilizados pela instrução $k$. Deste modo, basta determinar o custo base de cada instrução e o número de ciclos em que ela executa, para obter a potência média e a energia consumida pelo programa.

Os valores de corrente consumida por cada instrução são obtidos por medições feitas diretamente no hardware que contém o processador Nios II. Nas subseções seguintes, serão descritas detalhadamente as etapas de configuração, tanto do hardware quanto do software, para a aquisição precisa dos valores de corrente.

\subsubsection{Instrumentação e Configuração do Hardware}

Ao fazer o levantamento de dados sobre a corrente média consumida por cada instrução do processador Nios II, é necessário, primeiramente, instrumentar o hardware e configurar o FPGA de maneira apropriada para a realização das medições.

A placa de desenvolvimento utilizada neste trabalho de mestrado chama-se Nios II Evaluation Board (Figura 4.1). Ela contém um FPGA Cyclone EP1C12F324, memória SDRAM de 16MB e memória FLASH de 8MB. Apesar do Laboratório de Computação Reconfigurável possuir diversas placas de desenvolvimento, com FPGAs mais velozes e com um número maior de recursos, essa placa foi escolhida por ser a única a permitir, de maneira simples, a interceptação do pino de alimentação de energia do núcleo do FPGA. Essa característica permite medir a corrente consumida exclusivamente pelo FPGA, sem a interferência do consumo das memórias e dos demais dispositivos da placa.

A seguir, são descritos os detalhes sobre os processos de instrumentação física da placa de desenvolvimento e de configuração do processador soft-core Nios II, a fim de obter o perfil de 


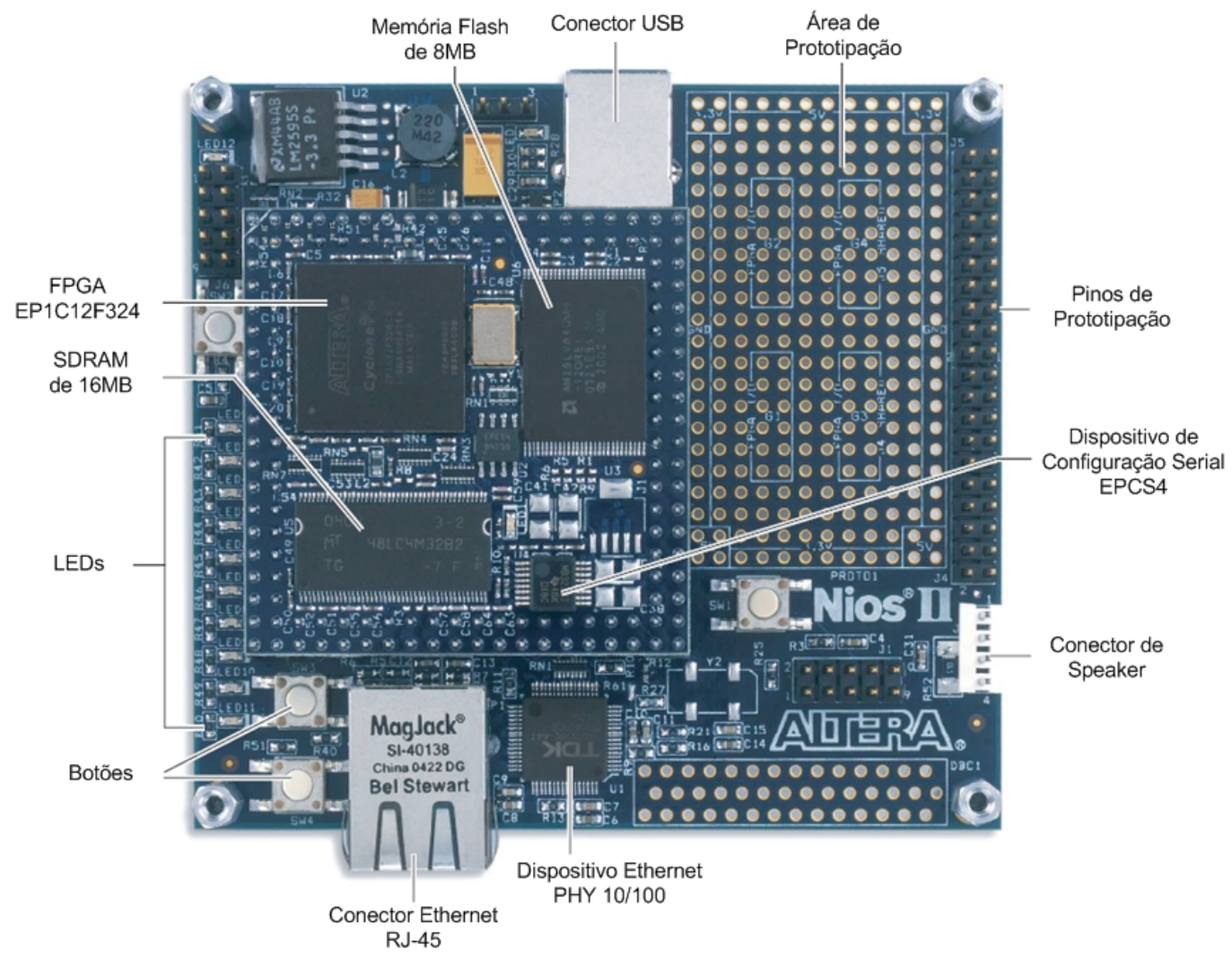

Figura 4.1: Visão detalhada da Nios II Evaluation Board

consumo de cada instrução.

\section{Instrumentação Eletrônica}

Para obtenção de medidas através da instrumentação eletrônica, foi implementado um setup que possibilitou a obtenção de valores de corrente consumida por cada instrução do processado Nios II. Interceptando o pino de alimentação do núcleo do FPGA, correspondente ao processador Nios II, foi possível realizar medidas da corrente consumida em tempo real.

A Nios II Evaluation Board é composta por dois módulos conectados entre si. Um deles é chamado de Placa de Prototipação e contém pinos de $\mathrm{I} / \mathrm{O}$, pinos para interface serial, pinos JTAG, botões e interface USB para configuração do FPGA e conexão com o computador host. Além disso, a placa possui um soquete para a conexão do módulo Firefly, criado pela empresa Microtronix (Microtronix, 2006). O módulos Firefly contém, basicamente, um dispositivo FPGA, memória FLASH, memória SDRAM e pinos de entrada e saída para encaixe com o soquete da Placa de Prototipação.

Toda a energia elétrica necessária para funcionamento do módulo Firefly provém da Placa 
de Prototipação. Vários pinos do módulo Firefly são utilizados para alimentação do FPGA e das memórias. A Figura 4.2 mostra a função de cada um dos pinos do módulo Firefly.

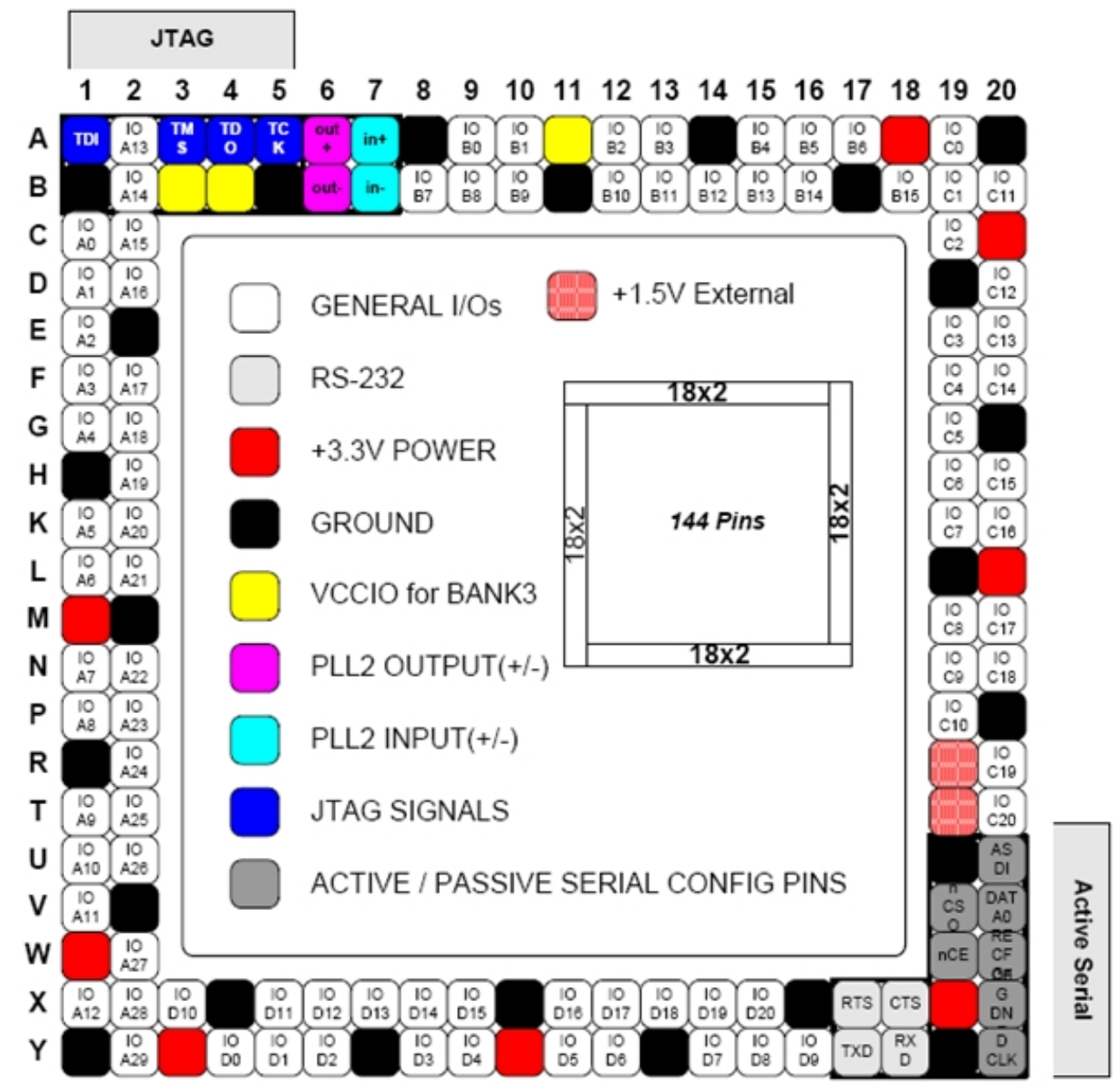

Figura 4.2: Função dos pinos do módulo Firefly

Além dos pinos de 3,3V que alimentam as memórias e os circuitos de $\mathrm{E} / \mathrm{S}$, há dois pinos de 1, 5V, R19 e T19, responsáveis pela alimentação do núcleo do FPGA. Para interceptá-los sem danificar os pinos originais do módulo, foi construída uma extensão formada por soquetes entre o modulo Firefly e a Placa de Prototipação (Figura 4.3).

Para realizar as medições, um resistor de $0,15 \Omega$ foi ligado em série com a conexão de alimentação do núcleo do FPGA de 1,5V da extensão. Inicialmente, as pontas de prova de um osciloscópio modelo TDS460A da Tektronix (Tektronix, 1995) foram conectadas às extremidades do resistor, configurando um medida diferencial entre os canais. Para sincronismo do osciloscópio, uma terceira ponta de prova conectada a um pino de E/S da Placa de Prototipação capta os sinais gerados pelo software, indicando o início e o fim do trecho de código sob análise. 


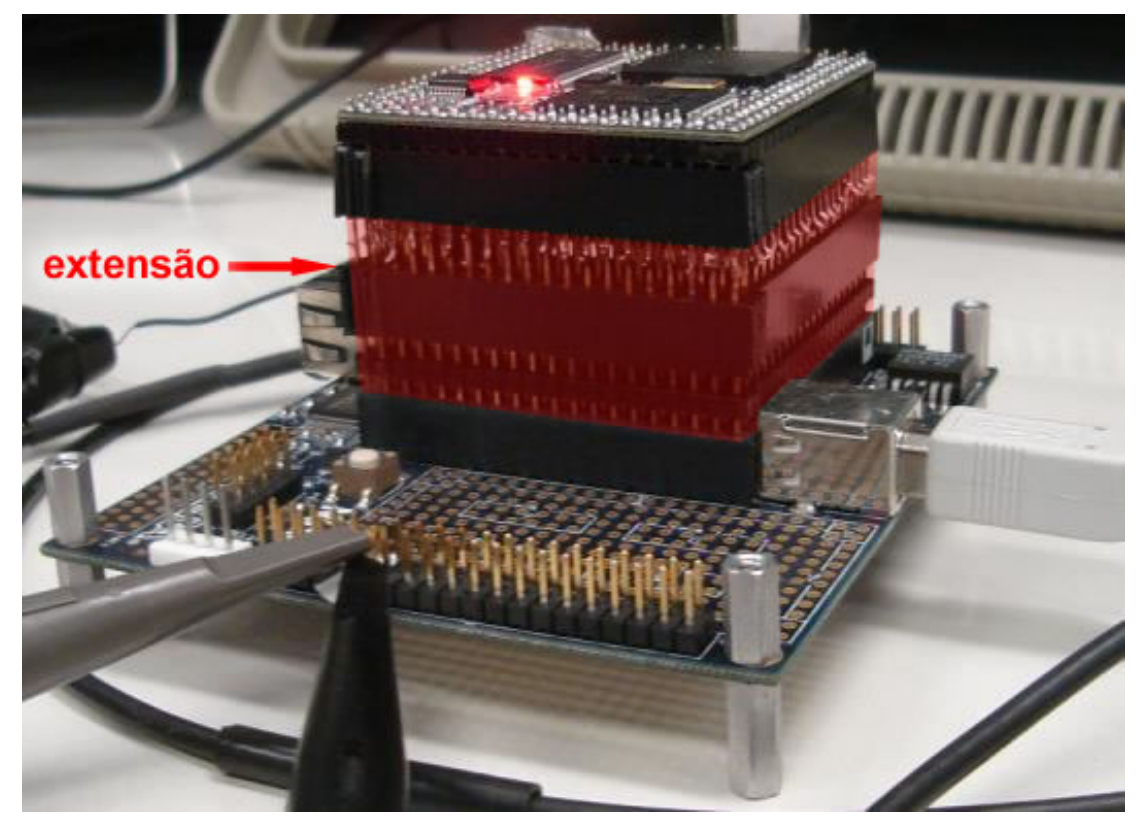

Figura 4.3: Extensão para interceptação dos pinos do módulo Firefly

Devido a baixa amplitude do sinal gerado sobre o resistor de $0,15 \Omega$, foi utilizado um pré-amplificador diferencial Tektronix ADA400A com alta rejeição de ruído de modo comum (Tektronix, 2001) para efetuar as medições.

O setup de medições utilizado é ilustrado pela Figura 4.4.

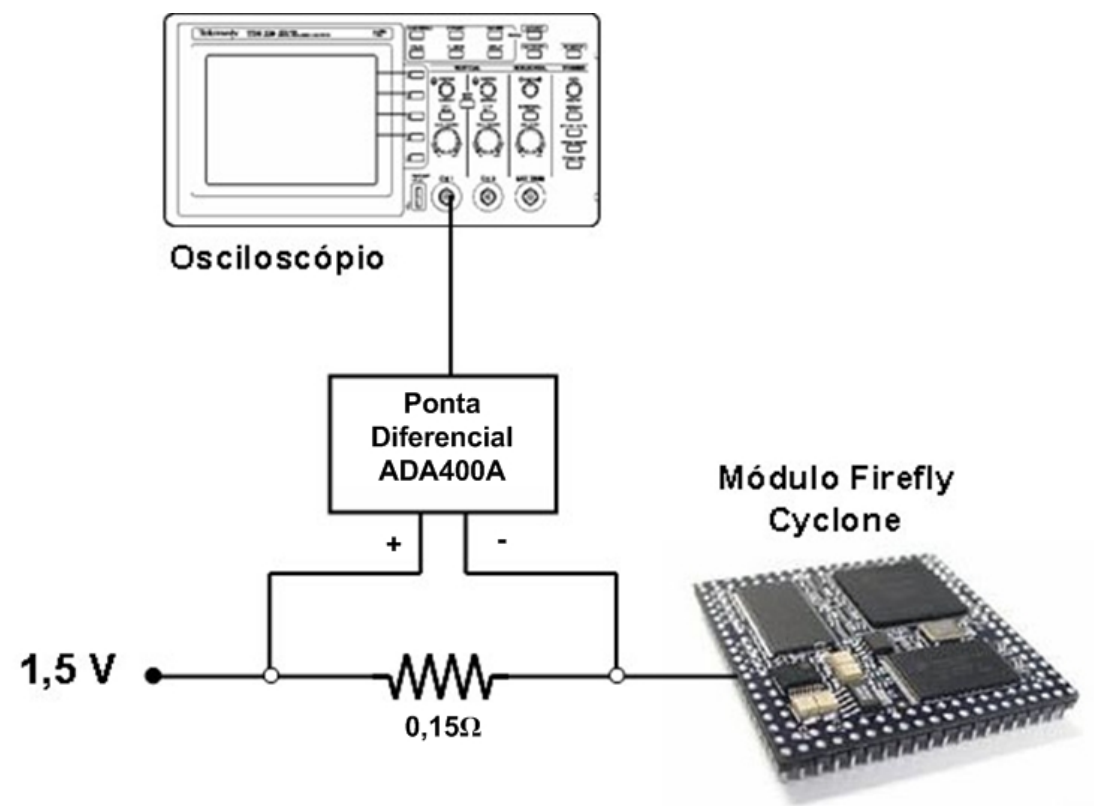

Figura 4.4: Setup para medições de corrente 


\section{Configuração do Processador}

Umas das grandes vantagens em se utilizar processadores soft-core, como o Nios II, está na possibilidade de adaptá-lo a aplicações específicas, de acordo com as restrições de espaço no FPGA e de frequiência de operação. A adaptação do processador Nios II às aplicações pode ser feita tanto pela inclusão/exclusão de periféricos quanto pela escolha de um dos três núcleos apresentados na Seção 2.3.

Neste trabalho, além da implementação do estimador de potência, são comparados os consumos entre os diferentes tipos de núcleo do Nios II. Para que os resultados dessa comparação sejam obtidos apenas pela diferença dos núcleos, todos os sistemas deverão conter o mesmo conjunto de periféricos. Por motivos de limitações no tempo desse projeto, serão comparados somente dois tipos de núcleo: o Economic e o Standard. A comparação com o núcleo Fast deverá seguir as mesmas etapas em um trabalho futuro.

A Figura 4.5 mostra a tela da ferramenta SOPC Builder com a lista de periféricos presentes em ambos os sistemas, Economic e Standard.

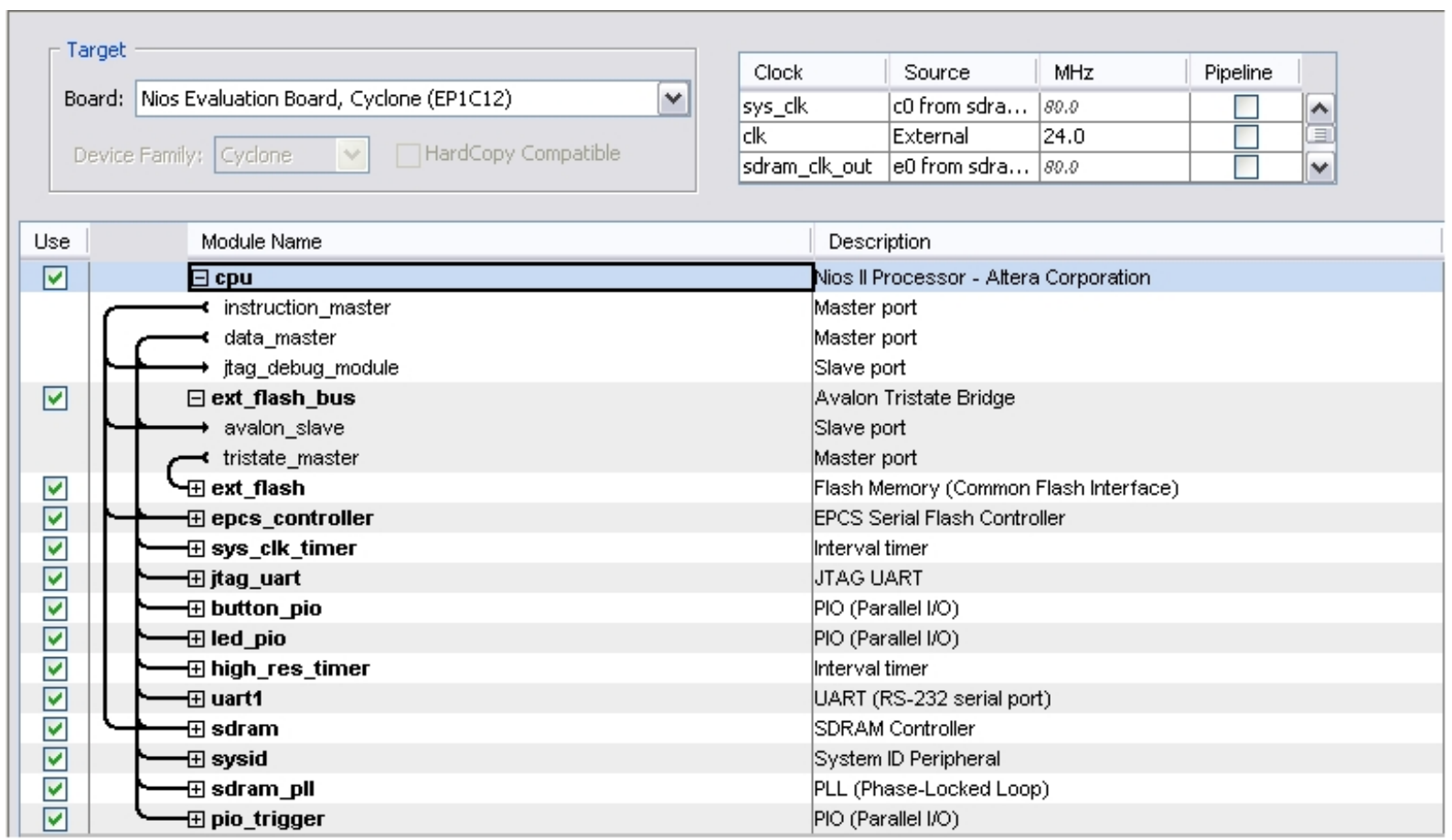

Figura 4.5: Lista de periféricos presentes em ambos os sistemas Economic e Standard

Dentre os periféricos presentes na lista da Figura 4.5, o chamado pio_trigger possui uma função específica para auxiliar no processo de medições das correntes. Ele está associado a um 
pino de saída da Placa de Prototipação e é utilizado para marcar o início e o fim de execução de um código no processador. Todos os programas executados no processador são carregados e armazenados na memória SDRAM externa.

São comparados também os consumos de corrente para diferentes frequiências de operação dos sistemas Economic e Standard. Para isso, foram criados sistemas com frequiências a 20, 40 e $80 \mathrm{MHz}$ para os dois tipos de núcleo.

O software Quartus II permite otimizar o hardware, durante a compilação, para área, velocidade ou um misto das suas otimizações. Neste trabalho, foi utilizada a opção de compilação padrão do software, que é velocidade. Uma possível comparação entre o consumo do hardware com as três otimizações não foi realizada e pode ser tema para trabalhos futuros.

\subsubsection{Configuração do Software}

Foram implementados dois conjuntos de programas com diferentes propósitos. O primeiro conjunto serve para traçar o perfil de consumo das instruções do processador Nios II e é um misto de programação em linguagem $\mathrm{C}$ e assembly. O outro conjunto tem o propósito de servir como base de teste para as estimações e é implementado em linguagem C.

Para essa tarefa, foi utilizado o ambiente integrado de desenvolvimento Eclipse, com modificações realizadas pela Altera especialmente para executar programas diretamente no processador Nios II, dentro do FPGA. Nas seguintes subseções serão mostrados os detalhes de implementação dos dois conjuntos de programas.

\section{Programas para Traçar Perfil de Consumo}

Dentro do contexto do modelo de estimação em nível de instrução, os programas utilizados para traçar o perfil de consumo de corrente de cada instrução consistem, basicamente, em um laço infinito contendo um certo número de instâncias da instrução de interesse.

O código mostrado na Figura 4.6 é um exemplo desse tipo de programa. Para cada instrução do processador Nios II considerada, foram implementados laços contendo mil instâncias. A execução desse número de instruções por iteração do laço é importante para a estabilização dos valores obtidos pelo osciloscópio, principalmente para o núcleo Standard do processador Nios 
II.

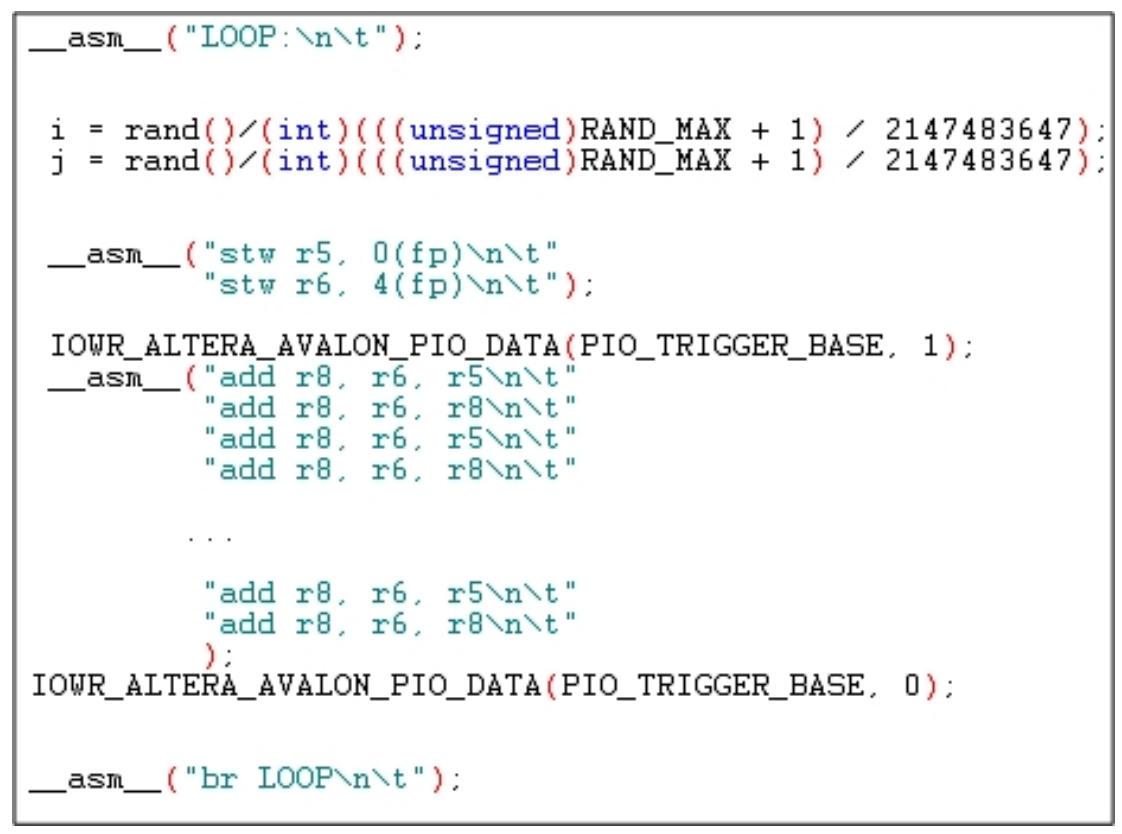

Figura 4.6: Programa para traçar o perfil de consumo de corrente da instrução ADD.

Para determinar o tempo exato de execução de cada iteração do laço, o programa realiza a ativação de um pino da Placa de Prototipação sempre que entra no laço, desativando-o ao sair. A função IOWR_ALTERA_AVALON_PIO_DATA (PIO_TRIGGER_BASE, X) realiza essa tarefa, onde X é igual a zero ou um, de acordo com o nível lógico desejado para o pino. Esse recurso também é de grande importância para o osciloscópio, uma vez que funciona como trigger para uma melhor definição dos valores medidos.

O laço infinito é implementado com instruções em assembly, de modo a interferir o mínimo possível nos resultados da medição. Um label (LOOP) é colocado no início do laço de mil instruções de interesse e uma instrução de desvio para esse label é colocada ao fim da laço.

Para que os dados de corrente média obtidos na medição fossem bastante representativos, os operandos de cada instrução eram modificados aleatoriamente a cada laço, utilizando a função rand(), definida na biblioteca stdlib.h da linguagem C.

Apesar do conjunto de instruções do processador Nios II possuir 94 instruções, apenas as 69 mais freqüentemente utilizadas foram consideradas para serem analisadas. Além de algumas instruções de controle, as instruções de multiplicação e divisão também não foram consideradas pois o hardware utilizado no experimento não oferecia suporte para estas instruções. 


\section{Programas de Teste}

O conjunto de programas de teste foi utilizado para verificar a precisão do estimador de potência implementado. Além disso, esses programas são instrumentos importantes para a realização de uma análise do consumo de energia e conseqüente melhoramento no modelo de estimação, como será visto em seções posteriores.

Cada programa de teste é um benchmark com características diferentes. A utilização de benchmarks para a realização de testes é importante pois, são padronizados e permitem uma comparação com os demais trabalhos relacionados. A seguir, é dada uma descrição breve da utilidade de cada programa de teste utilizado:

- ADPCM: é uma técnica para modulação de código de pulso (PCM) que converte sinais de som analógicos em informação digital. O algoritmo grava apenas a diferença entre as amostras, ajustando a escala de códigos automaticamente para acomodar pequenas e grandes variações. Tanto o algoritmo ADPCM codificador (ADPCM Cod) quanto o decoficador (ADPCM Dec) foram utilizados como programas de teste neste trabalho.

- Autocorrelação: é uma ferramenta matemática bastante utilizada em processamento de sinais que permite analisar funções ou uma série de valores, como por exemplo sinais no domínio de tempo. É útil para encontrar padrões de repetição em sinais, bem como identificar sua freqüência básica. O programa que implementa essa ferramenta matemática é indetificado neste trabalho por AUTCOR.

- DSP Vector Dot Product: é uma função utilizada em sistemas de processamento de sinais digitais que recebe dois vetores como entrada e calcula o produto desses vetores. Neste trabalho esse programa de teste está identificado como DSPDOTPROD.

- DSP Sum of Squares: é uma rotina utilizada em sistemas de processamento de sinais digitais que soma os quadrados dos elementos contidos em um vetor. Neste trabalho esse programa de teste será referenciado como DSPVECSUMSQ.

- DSP weighted Vector Sum: essa rotina faz uma soma ponderada de vetores. O nome utilizado para referenciar o programa neste trabalho é DSPWVEC. 
- FDCT: significa “Transformada Rápida Discreta de Cosseno". É um algoritmo bastante usado na área de processamento de imagens devido à sua característica de concentrar as informações dos sinais em poucos componentes de baixa freqüência.

- FFT: significa "Transformada Rápida de Fourier" e é muito utilizada em aplicações que vão de processamento digital de sinal a multiplicação de número inteiros.

- FIR: significa "Finite Impulse Response" e é uma classe de filtros utilizados em processamento digital de sinal cuja resposta a um pulso tende a zero em um espaço de tempo finito e previsível.

- GAXPY: essa rotina consiste em uma multiplicação do tipo matriz-vetor, a qual tem seu uso amplamente difundido especialmente em sistemas de processamento digital de sinais (DSP), onde é conhecida como a função MAC (Multiply and Accumulate).

- GOURAUD: rotina utilizada em computação gráfica para simular efeitos de luz e cor sobre a superfície de um objeto.

Assim como foi feito com os programas para traçar o perfil de consumo, os programas de teste foram colocados dentro de um laço infinito para possibilitar a leitura da corrente média no osciloscópio. O tempo de execução de cada programa também é determinado pelas mudanças de nível lógico do pino da Placa de Prototipação.

\subsubsection{Medições}

O conjunto de programas utilizado para traçar o perfil de consumo foi executado para dois tipos de configuração do processador Nios II: o núcleo Economic a $80 \mathrm{MHz}$ e o núcleo Standard a $80 \mathrm{MHz}$ e $4 \mathrm{~KB}$ de cache. Essas são configurações-padrão que já vêm com a instalação do processador Nios II.

A Figura 4.7 mostra um screen shot da tela do osciloscópio ao executar o programa para a instrução cmpge, utilizando o núcleo Economic. O comportamento da curva de diferença de voltagem é bastante estável durante toda a execução do laço, o que facilita a determinação do valor da corrente média. O sinal de sincronismo (acionado pelo pino da placa) permite 
determinar o tempo de execução do laço e, conseqüentemente, o número de ciclos de clock gastos, uma vez que a freqüência do processador é conhecida.

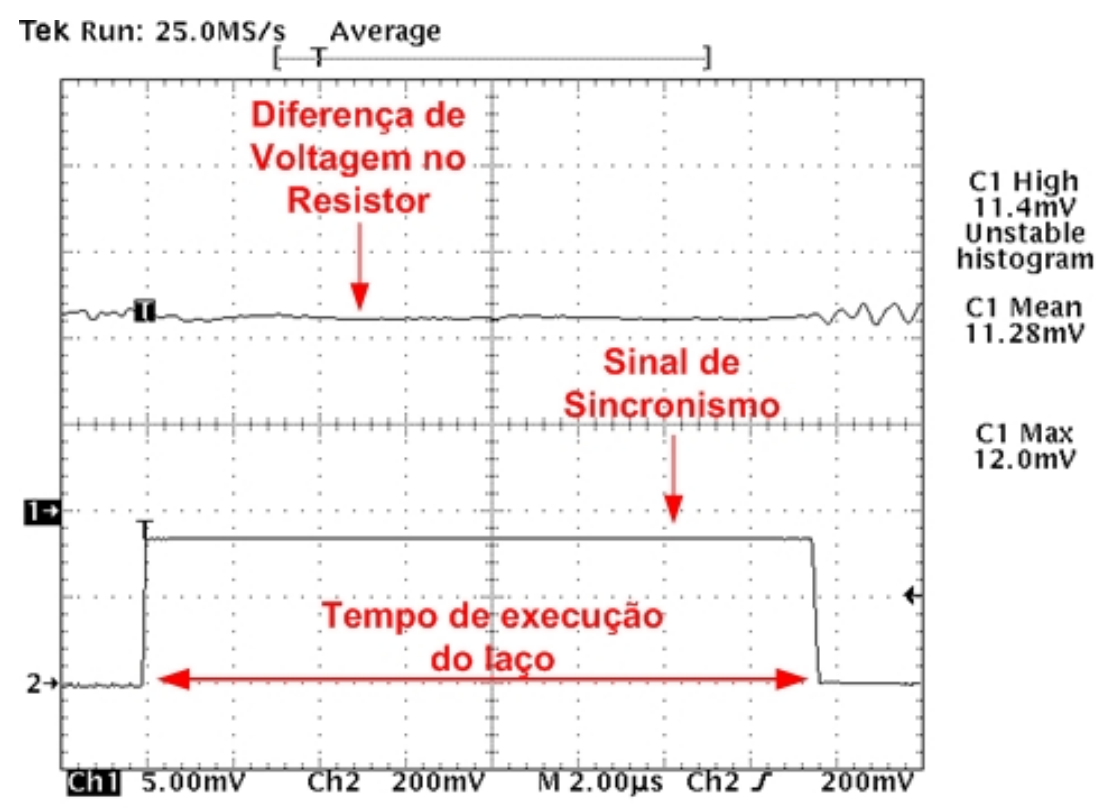

Figura 4.7: Medição da variação de corrente da instrução cmpge para o núcleo Economic

A Figura 4.8 mostra a execução da instrução cmpge, só que agora utilizando o núcleo Standard. O comportamento da curva de diferença de voltagem logo no começo da execução do laço é instável devido a indutâncias e capacitâncias internas ao FPGA. Após um certo número de instruções executadas o sinal se estabiliza.

O consumo de corrente de cada um dos programas de teste foi medido de maneira similar aos específicos de cada instrução. As tabelas com os valores de corrente média para cada instrução e para os programas de teste, executados tanto no núcleo Economic quanto no Standard, encontram-se no Apêndice A.

\subsection{Análise dos Resultados}

Terminada a etapa de medições, os dados presentes nas tabelas do Apêndice A foram analisados de modo a testar a eficácia do modelo de estimação proposto neste trabalho de mestrado. Assim, primeiramente serão analisados os dados obtidos para o processador Nios II de núcleo Economic e posteriormente para o processador de núcleo Standard. 


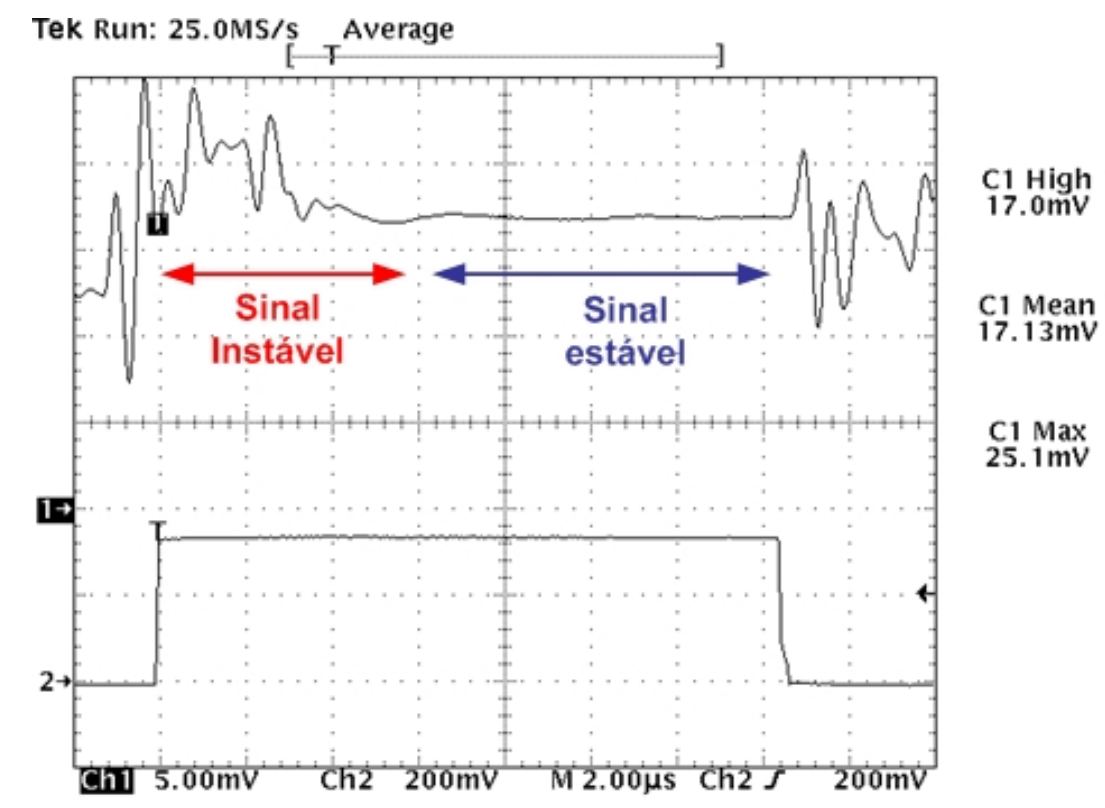

Figura 4.8: Medição da variação de corrente da instrução cmpge para o núcleo Standard

\subsubsection{Nios I/ Economic}

A Figura 4.9 mostra o consumo de corrente para todas as instruções avaliadas do processador Nios II com núcleo Economic. É interessante observar que os consumos de corrente são bastante uniformes, sendo que na média, as instruções consomem 0,075A. A variação total no consumo de corrente é de $0,015 \mathrm{~A}$, o que representa $20 \%$ do consumo médio de corrente.

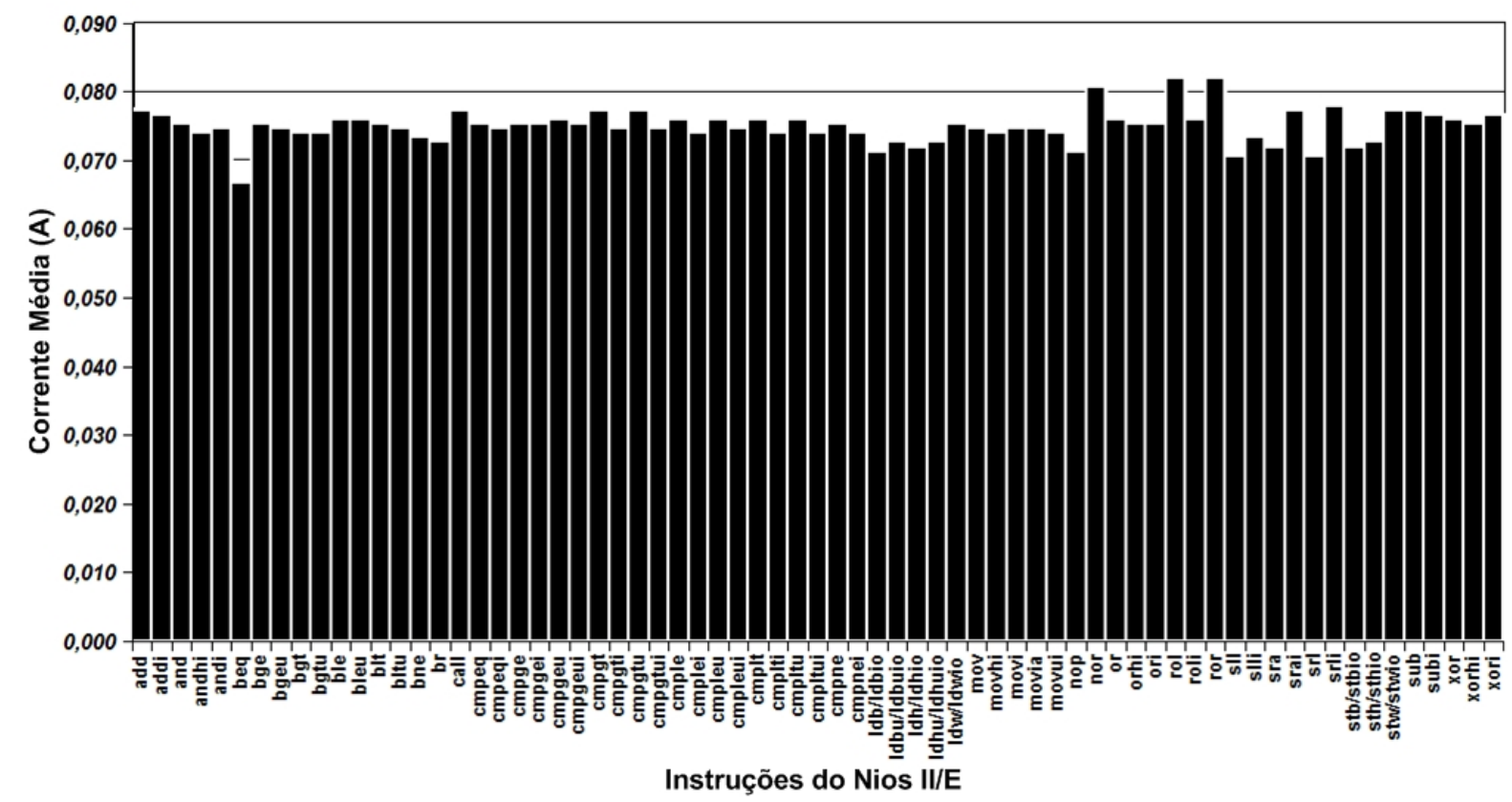

Figura 4.9: Consumo médio de corrente para cada instrução do núcleo Economic 
Ao considerar a variação de corrente entre os programas de teste, verifica-se que ela é ainda menor. A Figura 4.10 mostra o consumo de corrente para os onze diferentes programas de teste, com o processador funcionando em três níveis de freqüência diferentes. A média de consumo calculada para os programas é de $0,0768 \mathrm{~A}$, com uma variação de $0,001 \mathrm{~A}$, ou $1,43 \%$ para o núcleo a $80 \mathrm{MHz}$.

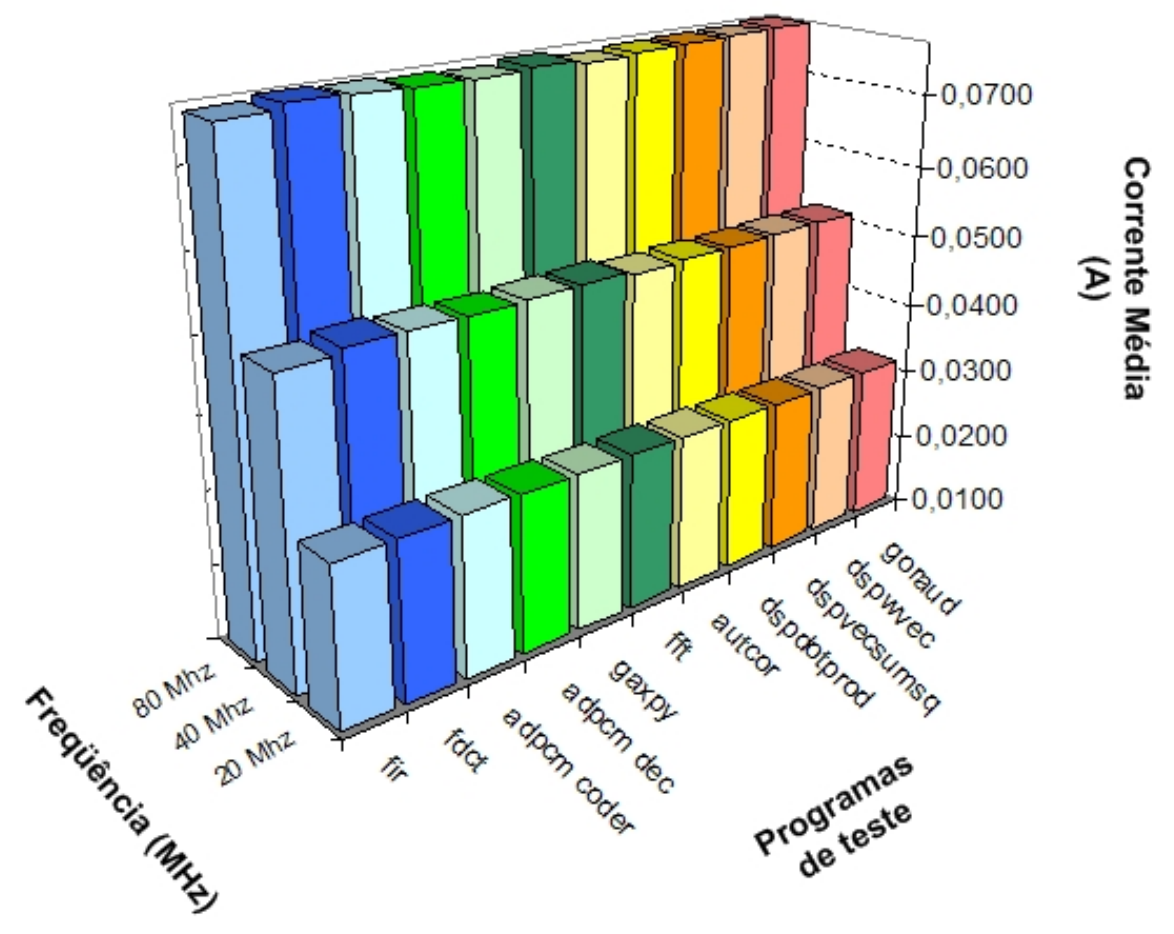

Figura 4.10: Consumo de corrente dos programas de teste em função da frequiência para o núcleo Economic

Segundo Sinha e Chandrakasan (2001), variações tão pequenas como essa implicam que o consumo de corrente de um trecho de código é dependente somente da voltagem e da freqüência do processador. Como a voltagem do FPGA é constante, pode-se afirmar que para o núcleo Economic, a estimação do consumo de energia dependerá apenas do tempo de execução do programa e da freqüência do processador, conforme a equação 4.6. Intuitivamente, a potência dissipada dependerá somente da freqüência.

$$
E=V_{c c} I_{m e d}(f) \times T
$$

na qual $I_{\text {med }}(f)$ é a corrente média consumida pelo processador operando na freqüência $f$. 
A Tabela 4.1 apresenta os valores de corrente média estimada para cada nível de freqüência analisado neste trabalho, bem como o erros de estimação máximos decorrentes da adoção desses valores.

Tabela 4.1: Média de consumo e erro associado dos programas de teste do núcleo Economic

\begin{tabular}{|c|c|c|}
\hline Freqüencia & $I_{\text {est }}$ & Erro max. \\
\hline \hline $20 \mathrm{MHz}$ & 0,03139 & $0,45 \%$ \\
\hline $40 \mathrm{MHz}$ & 0,05102 & $0,95 \%$ \\
\hline $80 \mathrm{MHz}$ & 0,07685 & $0,89 \%$ \\
\hline
\end{tabular}

O comportamento quase constante de consumo de energia, característico dessa configuração do Nios II, pode ser explicado pela simplicidade do seu núcleo. A ausência de pipelines e memórias cache torna o perfil de consumo do processador bastante previsível, pois somente uma instrução é buscada e executada por vez.

As ferramentas da Altera forneceram uma estimativa pouco precisa sobre o consumo de corrente tanto do núcleo Economic. Para o Nios II/S, a ferramenta PowerPlay Early Power Estimator estimou uma corrente média de 0,170A, enquanto que o PowerPlay Power Analyzer estimou em 0,120A.

\subsubsection{Nios // Standard}

A Figura 4.11 mostra o consumo de corrente para cada uma das instruções avaliadas do processador Nios II Standard com $4 \mathrm{~KB}$ de cache e $80 \mathrm{MHz}$ de frequiência. Ao contrário do que ocorre com o núcleo Economic, o Standard apresenta uma grande variação nos consumos de corrente das instruções, as quais em média consomem 0,102A. A variação total é de $0,085 \mathrm{~A}$ e representa $83,2 \%$ do consumo médio de corrente.

Da mesma forma, a variação de consumo médio de corrente entre os programas também é grande, chegando a 32,7\% ou 0,0295A. A Figura 4.12 mostra o consumo de corrente para os onze diferentes programas de teste, com o processador funcionando em três níveis de frequiência diferentes. A média de consumo calculada para os programas é de 0,09019A. A Tabela 4.3 apresenta a média de consumo de corrente para cada nível de frequiência analisado e os erros máximos, caso esses valores fossem adotados como estimação da corrente. 


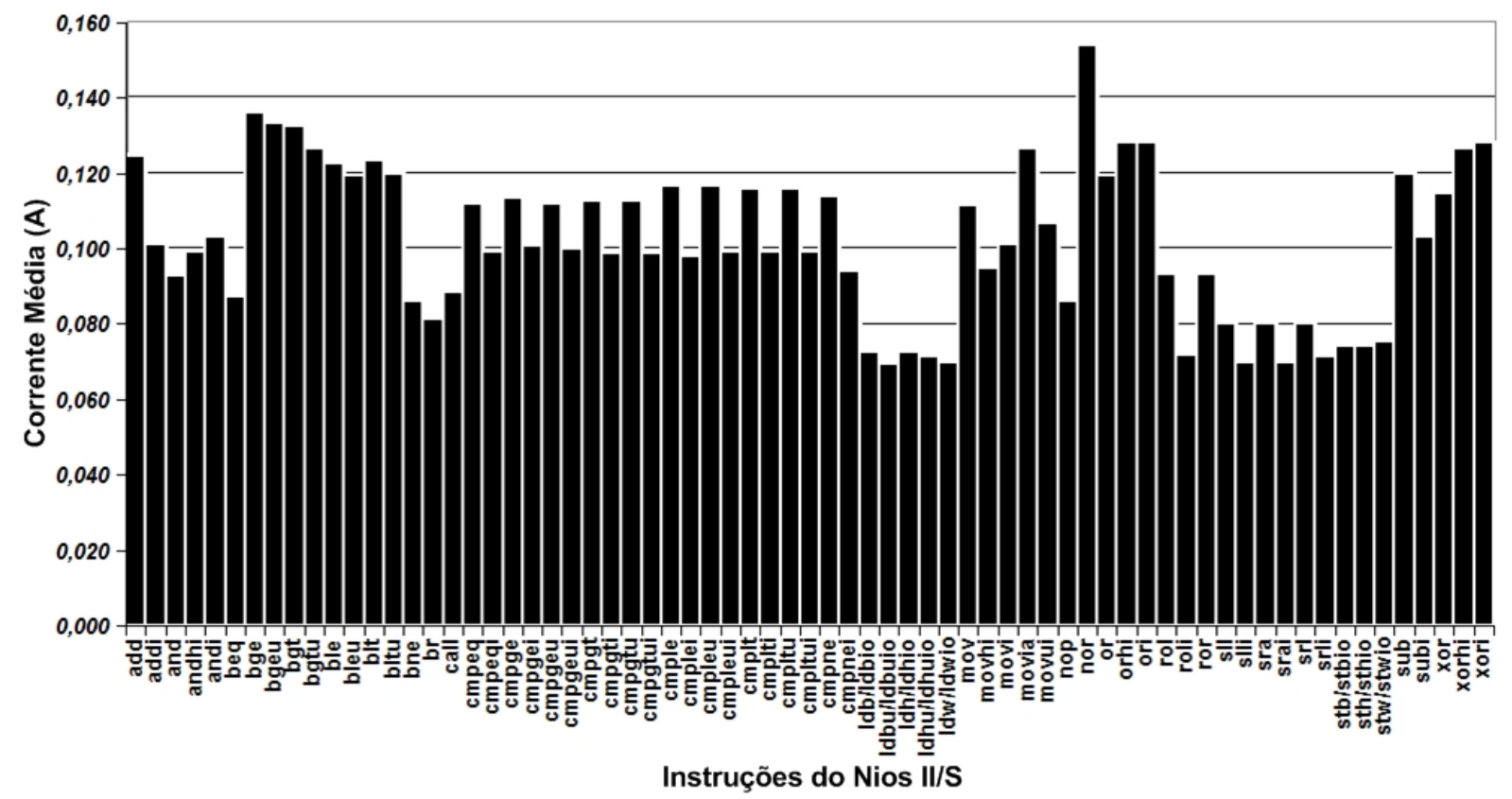

Figura 4.11: Consumo médio de corrente para cada instrução do núcleo Standard

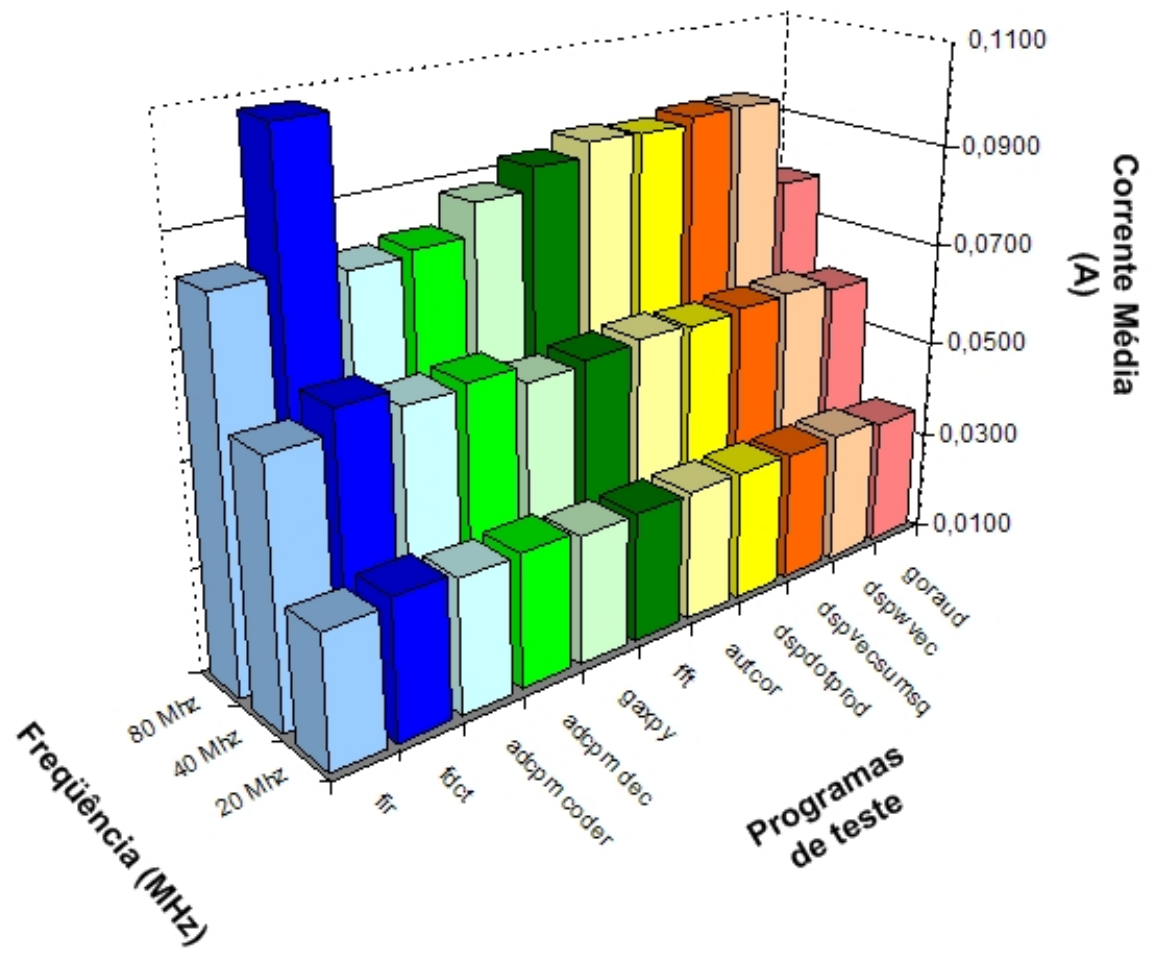

Figura 4.12: Consumo de corrente dos programas de teste em função da frequiência para o núcleo Standard

Nesse caso, como as variações de corrente são significativas, a média das correntes dos programas de teste não representa uma boa estimativa. Considerando o perfil de consumo de 
Tabela 4.2: Média de consumo e erro associado dos programas de teste do núcleo Standard

\begin{tabular}{|c|c|c|}
\hline Freqüencia & Média das correntes & Erro max. \\
\hline \hline $20 \mathrm{MHz}$ & 0,03562 & $1,93 \%$ \\
\hline $40 \mathrm{MHz}$ & 0,06089 & $5,4 \%$ \\
\hline $80 \mathrm{MHz}$ & 0,09019 & $19,52 \%$ \\
\hline
\end{tabular}

cada instrução do núcleo Standard, aplicou-se o modelo de estimação de potência desenvolvido neste trabalho de mestrado a cada programa de teste. A Tabela 4.3 apresenta as estimações das correntes médias e o erro dessas estimações para cada programa.

Tabela 4.3: Comparação entre os valores de corrente reais e estimadas dos programas de teste do núcleo Standard

\begin{tabular}{|c|c|c|c|}
\hline Programa & Corrente Real (A) & Corrente Estimada (A) & Erro \\
\hline \hline FIR & 0,0827 & 0,0809 & $2,17 \%$ \\
\hline FDCT & 0,1078 & 0,1025 & $4,91 \%$ \\
\hline ADPCM Cod & 0,081 & 0,0765 & $5,55 \%$ \\
\hline ADPCM Dec & 0,082 & 0,076 & $7,31 \%$ \\
\hline GAXPY & 0,0879 & 0,082 & $6,71 \%$ \\
\hline FFT & 0,092 & 0,0864 & $6,08 \%$ \\
\hline AUTCOR & 0,0947 & 0,0867 & $8,44 \%$ \\
\hline DSPDOTPROD & 0,0943 & 0,0928 & $1,59 \%$ \\
\hline DSPVECSUMSQ & 0,0957 & 0,0926 & $3,23 \%$ \\
\hline DSPWVEC & 0,0957 & 0,0924 & $3,44 \%$ \\
\hline GORAUD & 0,0783 & 0,0748 & $4,47 \%$ \\
\hline
\end{tabular}

O erro máximo de estimação obtido foi de 8,44\%. O gráfico da Figura 4.13 mostra a eficácia do modelo de estimação em acompanhar o perfil de consumo de cada programa de teste.

Apesar do modelo fornecer uma estimação razoavelmente precisa, alguns fatores que influenciam o consumo de energia foram ignorados, como por exemplo, o consumo inter-instruções e pipeline stalls. A omissão desses fatores faz com que os valores estimados sejam sempre menores que os valores reais. A fim de tentar compensar o consumo não calculado desses fatores, torna-se interessante utilizar um fator de ajuste para melhorar a precisão da estimação.

Por exemplo, pode-se somar à equação de corrente média, a média aritmética dos valores correspondentes aos erros de estimação. Tal exemplo puramente empírico leva aos resultados dispostos na Tabela 4.4 .

A utilização do fator de ajuste permitiu reduzir em $43 \%$ o valor do erro máximo, que caiu para 4,78\%. O gráfico da Figura 4.14 permite comparar as medidas de corrente real, a corrente 


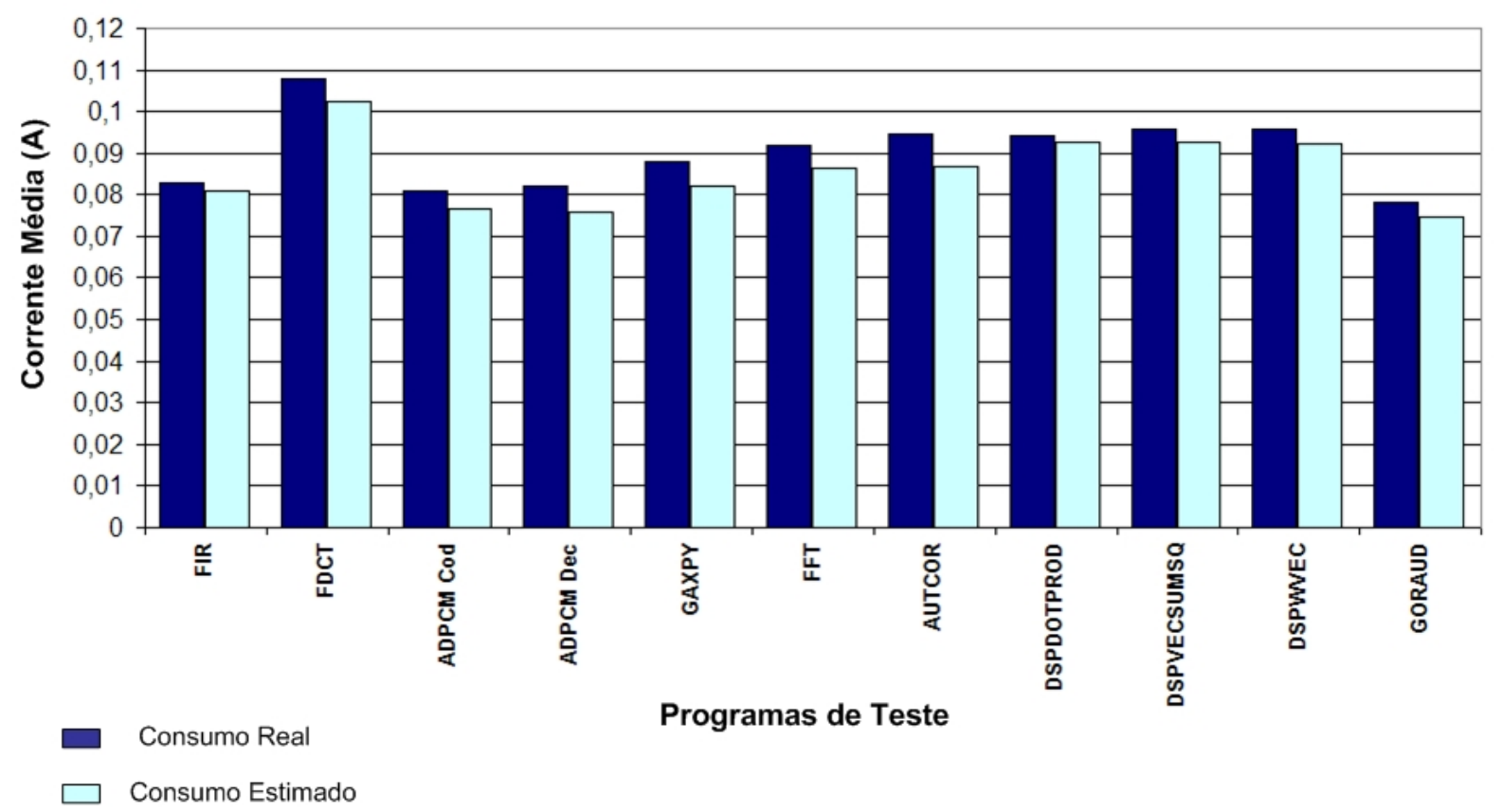

Figura 4.13: Comparação entre os consumos de corrente real e estimado para o núcleo Standard estimada e a corrente estimada com a adição do fator de ajuste para cada programa de teste.

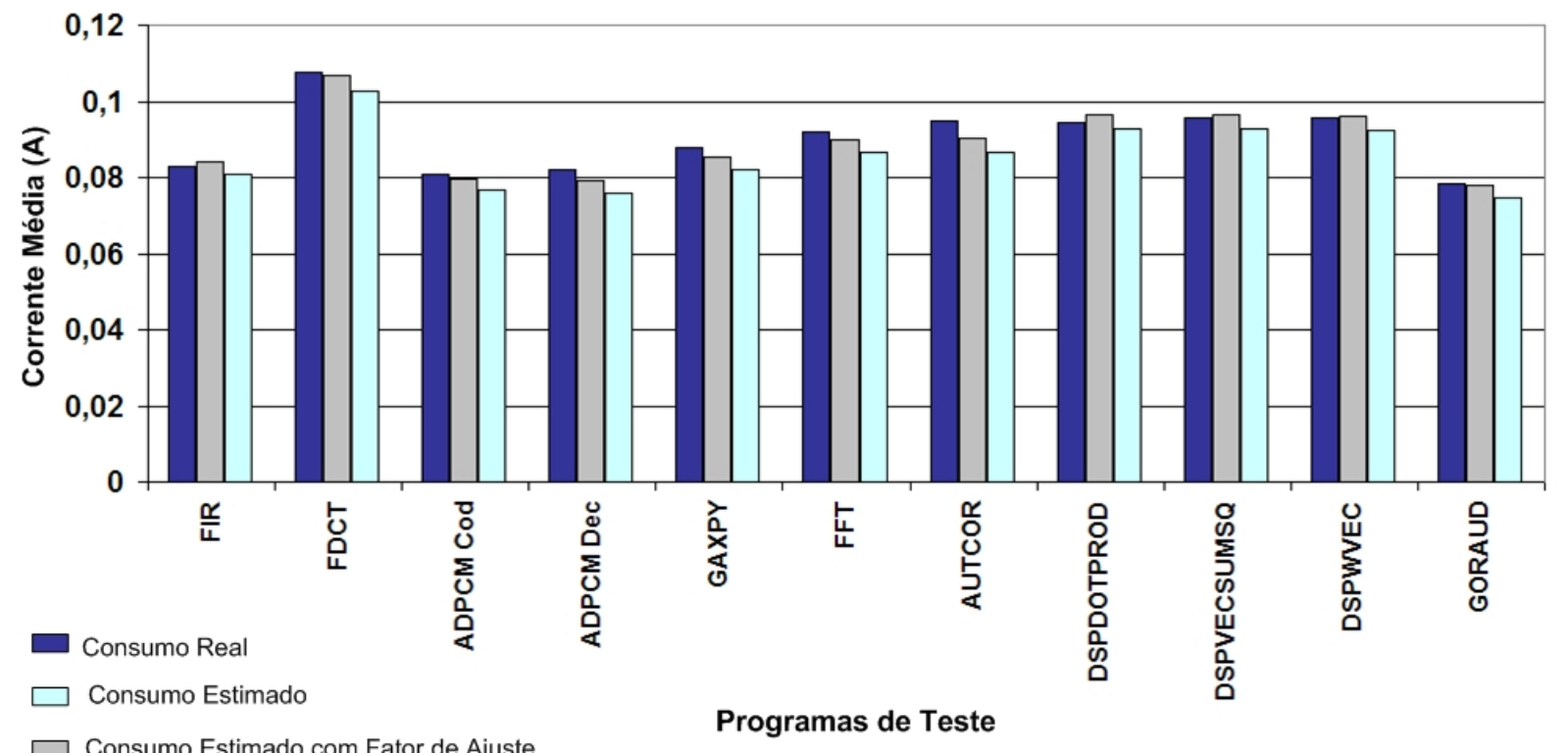

Figura 4.14: Comparação entre os consumos de corrente real, estimado e estimado com fator de ajuste.

Assim como para o núcleo Economic, as ferramentas da Altera forneceram uma estimativa pouco precisa sobre o consumo de corrente do núcleo Standard. Para o Nios II/S, a ferramenta PowerPlay Early Power Estimator estimou uma corrente média de 0,170A, enquanto que o PowerPlay Power Analyzer estimou em 0,160A. 
Tabela 4.4: Comparação entre os valores de corrente reais e estimadas dos programas de teste do núcleo Standard, utilizando o fator de ajuste.

\begin{tabular}{|c|c|c|c|}
\hline Programa & Corrente Real (A) & Corrente Estimada (A) & Erro \\
\hline \hline FIR & 0,0827 & 0,0841 & $1,73 \%$ \\
\hline FDCT & 0,1078 & 0,1066 & $1,11 \%$ \\
\hline ADPCM Cod & 0,081 & 0,0795 & $1,77 \%$ \\
\hline ADPCM Dec & 0,082 & 0,0790 & $3,61 \%$ \\
\hline GAXPY & 0,0879 & 0,0852 & $2,98 \%$ \\
\hline FFT & 0,092 & 0,0898 & $2,33 \%$ \\
\hline AUTCOR & 0,0947 & 0,0901 & $4,78 \%$ \\
\hline DSPDOTPROD & 0,0943 & 0,0996 & $2,34 \%$ \\
\hline DSPVECSUMSQ & 0,0957 & 0,0963 & $0,63 \%$ \\
\hline DSPWVEC & 0,0957 & 0,0960 & $0,41 \%$ \\
\hline GORAUD & 0,0783 & 0,0777 & $0,64 \%$ \\
\hline
\end{tabular}





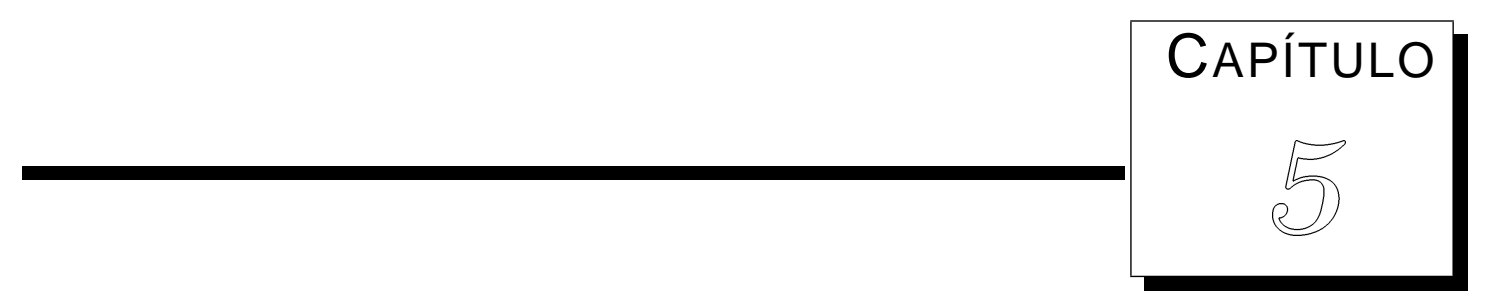

\section{Conclusão}

O modelo proposto neste trabalho, baseado no método de estimação em nível de instrução, provou ser bastante adequado para estimar a corrente média consumida por um programa executado no processador Nios II, implementado em um circuito FPGA. Esse método foi escolhido dentre as diversas técnicas de estimação de potência principalmente por poder ser reproduzido com uma maior facilidade no Laboratório de Computação reconfigurável. Além disso, o método atua somente em nível software, podendo ser facilmente adaptado a outros processadores ou núcleos do Nios II. A metodologia utilizada possibilitou a implementação de um modelo de estimação preciso. Os erros obtidos, 4,78\% para o núcleo Standard e 0,89\% para o núcleo Economic, puderam ser considerados aceitáveis e comparativamente similares aos erros de outros trabalhos relacionados a outros processadores.

Cabe ressaltar que este trabalho tem uma contribuição inovadora, uma vez que não que são conhecidos na literatura, trabalhos similares com processadores soft-core e nem com o Nios II. Sua contribuição para o ARCHITECT+ é de grande relevância e irá ajudar o LCR a dimensionar o consumo de energia e conseqüentemente, o tamanho da bateria do robô móvel que está sendo projetado baseado em computação reconfigurável.

Por último, os problemas operacionais de teste e medição demonstraram uma complexidade 
enorme, cujos desafios inicialmente pareciam insuperáveis. Entretanto, com muito conhecimento e perseverança, o trabalho foi concluído com êxito.

\subsection{Trabalhos Futuros}

Alguns trabalhos que poderiam ser desenvolvidos para se complementar o projeto seriam:

- Integrar o monitor de hardware que está em desenvolvimento (Ravagnani, 2007) ao estimador, de modo que a contagem das instruções seja feita automaticamente.

- Completar o conjunto de instruções, de modo a conseguir um modelo mais abrangente e executar benchmarks mais complexos.

- Expandir o modelo para estimar o consumo de instruções customizadas do Nios II.

- Expandir o modelo para processamento multicore baseado no Nios II.

- Integrar o modelo do estimador ao fluxo da ferramenta ARCHITECT+.

- Aplicar técnicas de aprendizado de máquina sobre os dados de consumo das instruções e dos programas de teste para desenvolver um modelo de estimação mais preciso. 


\section{Referências Bibliográficas}

AlterA Sopc builder data sheet v.2.0. Altera Corporation, 2003.

ALTERA Nios ii processor reference handbook. Altera Corporation, 2005a.

AlterA Quartus ii handbook volume 3. Altera Corporation, 2005b.

Bonato, V.; Sanches, A. K.; Fernandes, M.; Cardoso, J. M. P.; Simões, E.; MarQUES, E. A real time gesture recognition system for mobile robots. In: Proceedings of the International Conference on Informatics in Control, Automation, and Robotics (ICINCO04), Portugal, 2004, p. $207-214$.

Bondalapati, K.; Prasanna, V. K. Reconfigurable computing systems. In: Proceedings of the IEEE, 2002, p. 1201-1217.

Brandolese, C.; Fornaciari, W.; Salice, F.; Sciuto, D. An instruction-level functionality-based energy estimation model for 32-bits microprocessors. In: Proceedings of the Annual ACM IEEE Design Automation Conference, 2000, p. 346-351.

Chang, N.; Kim, K.; LeE, H. G. Cycle-accurate energy consumption measurement and analysis: case study of arm7tdmi. In: Proceedings of the 2000 International Symposium on Low Power Electronics and Design, Rappallo, Italy, 2000, p. 185-190.

Chen, R. Y.; IRWIN, M. J.; BAJWA, R. S. An architectural level power estimator. In: Proceedings of the Power-Driven Microarchitecture Worksho, 1998. 
COMPton, K.; HaUCK, S. An introduction to reconfigurable computing. IEEE Computer, 2000a.

Compton, K.; Hauck, S. Reconfigurable computing: A survey of systems and software. ACM Computing Surveys, v. 34, n. 2, p. 171-210, $2000 \mathrm{~b}$.

DeHon, A.; WAWrzyneK, J. Reconfigurable computing: What, why, and implications for design automation. In: Proceedings of Design Automation Conference, New Orleans, 1999, p. 610-615.

DuARTE, F. L. Phoenix - um framework para trabalhos em sintese de alto nível de circuitos digitais. Dissertação de mestrado, Universidade Federal de Uberlândia, Uberlândia, Brasil, 2006.

Estrin, G.; Bussell, B.; TuRn, R.; BiBB, J. Parallel processing in a restructurable computer system. IEEE Transactions on Electronic Computers, v. EC-12, n. 5, p. 747-755, 1963.

Gebotys, C. H.; Gebotys, R.; Wiratunga, S. Power minimization derived from architectural-usage of vliw processors. In: Proceedings of the Annual ACM IEEE Design Automation Conference, 2000, p. 308-311.

Gebotys, C. H.; Gebotys, R. J. An empirical comparison of algorithmic, instruction, and architectural power prediction models for high performance embedded dsp processors. In: Proceedings of the International Symposium on Low Power Eletronics and Design, 1998.

Hamblen, J. O.; Furman, M. D. Rapid prototyping of digital systems. 2 ed. Boston: Kluwer Academic Publishers, 2001.

Hodjat, A. Survey of some power estimation tools (jouletrack, simplepower, pact), 2001. Disponível em http://www.ee.ucla.edu/ ahodjat/ee202a/hw1/hw1.html (Acessado em Março de 2006)

de Holanda, J. A.; de Almeida, L. O. B.; Bonato, V.; Cardoso, J. M. P.; Marques, 
E. Determinação do perfil de consumo de potência em nível de instrução para processadores soft-core. In: III Jornadas sobre sistemas reconfiguráveis, 2007, p. 60-65.

De Holanda, J. A.; Peron, R.; Marques, E. Uma metodologia para análise de desempenho e códigos executados no processador nios ii. In: Actas das II Jornadas sobre Sistemas Reconfiguráveis, Porto, Portugal, 2006, p. 23 - 30.

Klass, B.; Thomas, D. E.; Schmit, H.; ; Nagle., D. F. Modeling inter-instruction energy effects in a digital signal processor. In: Proceedings of the Power-Driven Microarchitecture Workshop, 1998.

LATTICE Latticemico32 processor reference manual. Lattice Semiconductor Corporation, 2006.

Lee, M. T.-C.; Fujita, M.; Tiwari, V.; Malik, S. Power analysis and minimization techniques for embedded dsp software. IEEE Trans. Very Large Scale Integr. Syst., v. 5, n. 1, p. 123-135, 1997.

Lee, S.; Ermedahl, A.; Min, S. L.; Chang, N. An accurate instruction-level energy consumption model for embedded risc processors. In: Proceedings of The Workshop on Languages, Compilers, and Tools for Embedded Systems (LCTES 2001), 2001, p. 1-10.

LYONS, D. Holy chip!, 2006.

Disponível em www.forbes.com/forbes/2006/0130/076.html (Acessado em Março de 2006)

Mehta, H.; Owens, R. M.; IRwin, M. J. Instruction level power profiling. In: Proceedings of the International Conference on Acoustics, Speech and Signal Processing, 1996.

MicRotronix Firefly configurable processor brochure. 2006.

Nikolaidis, S.; Chatzigeorgiou, A.; Laopoulos, T. Developing an environment for embedded software energy estimation. Computer Standards and Interfaces, v. 28, n. December, p. 150-158, 2005. 
Ravagnani, G. S. Projeto de um módulo para monitoramento de $h w / s w$ on-chip baseado em computação reconfigurável. Dissertação de mestrado, Universidade de São Paulo, 2007.

RUSSELL, J.; JACOME, M. Software power estimation and optimization fbr high-performance 32-bit embedded processors. In: Proc. Int. Conf. Computer Design, 1998, p. 328 - 333.

Sami, M.; Sciuto, D.; Silvano, C.; ZacCARIA, V. Instruction-level power estimation for embedded vliw cores. In: Proceedings of the Eighth International Workshop on Hardware/Software Codesign, 2000, p. 34-38.

Sinha, A.; ChandRAKASAN, A. Jouletrack - a web based tool for software energy profiling. In: Proceedings of the 38th Design Automation Conference, DAC, Las Vegas, Nevada, USA, 2001, p. 220-225.

TEKTRONIX Tds 410a, tds 420a \& tds 460a digitizing oscilloscopes - user manual. 1995.

TEKTRONIX Ada400a differential preamplifier - instruction manual. 2001.

Tiwari, V.; Malik, S.; ; Wolfe, A. Power analysis of embedded software: a first step towards software power minimization. IEEE Transactions on Very Large Scale Integration (VLSI) Systems, v. 2, n. 4, p. 437-445, 1994.

XILINX Microblaze processor reference guide. Xilinx Inc., 2006.

Ye, W.; ViJAYKRIShnAN, N.; KAndemir, M.; IRWin, M. J. The design and use of simplepower: A cycle-accurate energy estimation tool. In: Proceedings of the Annual ACM IEEE Design Automation Conference, 2000, p. 340-345. 


\section{Apêndice A}

Tabela com o consumo médio de corrente (A) por instrução (custo base) para o processador Nios II com o núcleo Economic.

\begin{tabular}{l|cll|l|c} 
Instruçöes & Corrente média & Instruçöes & Corrente média & Instruçöes & Corrente média \\
add & 0,077 & cmpgt & 0,077 & movui & 0,074 \\
addi & 0,077 & cmpgti & 0,075 & nop & 0,071 \\
and & 0,075 & cmpgtu & 0,077 & nor & 0,081 \\
andhi & 0,074 & cmpgtui & 0,075 & or & 0,076 \\
andi & 0,075 & cmple & 0,076 & orhi & 0,075 \\
beq & 0,067 & cmplei & 0,740 & ori & 0,075 \\
bge & 0,075 & cmpleu & 0,076 & rol & 0,082 \\
bgeu & 0,075 & cmpleui & 0,075 & roli & 0,076 \\
bgt & 0,074 & cmplt & 0,076 & ror & 0,082 \\
bgtu & 0,074 & cmplti & 0,074 & sll & 0,071 \\
ble & 0,076 & cmpltu & 0,076 & slli & 0,073 \\
bleu & 0,076 & cmpltui & 0,074 & sra & 0,072 \\
blt & 0,075 & cmpne & 0,075 & srai & 0,077 \\
bltu & 0,075 & cmpnei & 0,074 & srl & 0,071 \\
bne & 0,073 & Idb/ldbio & 0,071 & srli & 0,078 \\
br & 0,073 & Idbu/ldbuio & 0,073 & stb/stbio & 0,072 \\
call & 0,077 & Idh/ldhio & 0,072 & sth/sthio & 0,073 \\
cmpeq & 0,075 & Idhu/ldhuio & 0,073 & stw/stwio & 0,077 \\
cmpeqi & 0,075 & Idw/ldwio & 0,075 & sub & 0,077 \\
cmpge & 0,075 & mov & 0,075 & subi & 0,077 \\
cmpgei & 0,075 & movhi & 0,074 & xor & 0,076 \\
cmpgeu & 0,076 & movi & 0,075 & xorhi & 0,075 \\
cmpgeui & 0,075 & movia & 0,075 & xori & 0,077
\end{tabular}


Tabela com o consumo médio de corrente (A) por instrução (custo base) para o processador Nios II com o núcleo Standard.

\begin{tabular}{|c|c|c|c|c|c|}
\hline Instruçōes & Corrente média & Instruçöes & Corrente média & Instruçŏes & Corrente média \\
\hline add & 0,125 & cmpgt & 0,113 & movui & 0,107 \\
\hline addi & 0,101 & cmpgti & 0,099 & nop & 0,086 \\
\hline and & 0,093 & cmpgtu & 0,113 & nor & 0,154 \\
\hline andhi & 0,099 & cmpgtui & 0,099 & or & 0,119 \\
\hline andi & 0,103 & cmple & 0,117 & orhi & 0,128 \\
\hline beq & 0,087 & cmplei & 0,098 & ori & 0,128 \\
\hline bge & 0,136 & cmpleu & 0,117 & rol & 0,093 \\
\hline bgeu & 0,133 & cmpleui & 0,099 & roli & 0,072 \\
\hline bgt & 0,133 & cmplt & 0,116 & ror & 0,093 \\
\hline bgtu & 0,127 & cmplti & 0,099 & sll & 0,080 \\
\hline ble & 0,123 & cmpltu & 0,116 & slli & 0,070 \\
\hline bleu & 0,119 & cmpltui & 0,099 & sra & 0,080 \\
\hline blt & 0,123 & cmpne & 0,114 & srai & 0,070 \\
\hline bltu & 0,120 & cmpnei & 0,094 & srl & 0,080 \\
\hline bne & 0,086 & Idb/ldbio & 0,073 & srli & 0,071 \\
\hline br & 0,081 & Idbu/ldbuio & 0,069 & stb/stbio & 0,074 \\
\hline call & 0,089 & Idh/ldhio & 0,073 & sth/sthio & 0,074 \\
\hline cmpeq & 0,112 & Idhu/ldhuio & 0,071 & stw/stwio & 0,075 \\
\hline cmpeqi & 0,099 & Idw/ldwio & 0,070 & sub & 0,120 \\
\hline cmpge & 0,113 & mov & 0,111 & subi & 0,103 \\
\hline cmpgei & 0,101 & movhi & 0,095 & xor & 0,115 \\
\hline cmpgeu & 0,112 & movi & 0,101 & xorhi & 0,127 \\
\hline cmpgeui & 0,100 & movia & 0,127 & xori & 0,128 \\
\hline
\end{tabular}

Tabela com o consumo médio de corrente (A) por programa de teste para o processador Nios II com o núcleo Economic.

\begin{tabular}{lccc}
\cline { 2 - 3 } Programas de Teste & $\mathbf{8 0 ~ M H z}$ & $\mathbf{4 0} \mathbf{~ M H z}$ & $\mathbf{2 0 M H z}$ \\
\cline { 2 - 3 } fir & 0,0765 & 0,0505 & 0,0313 \\
fdct & 0,0775 & 0,0513 & 0,0315 \\
adpcm coder & 0,0769 & 0,0511 & 0,0315 \\
adpcm decoder & 0,0766 & 0,0509 & 0,0314 \\
gaxpy & 0,0765 & 0,0511 & 0,0314 \\
fft & 0,0770 & 0,0513 & 0,0315 \\
autcor & 0,0764 & 0,0507 & 0,0313 \\
dspdorprod & 0,0768 & 0,0509 & 0,0313 \\
dspvecsumsq & 0,0769 & 0,0510 & 0,0313 \\
dspwvec & 0,0770 & 0,0511 & 0,0313 \\
gouraud & 0,0772 & 0,0512 & 0,0315
\end{tabular}


Tabela com o consumo médio de corrente (A) por programa de teste para o processador Nios II com o núcleo Standard.

\begin{tabular}{lccc}
\hline Programas de Teste & $\mathbf{8 0} \mathbf{~ M H z}$ & $\mathbf{4 0} \mathbf{~ M H z}$ & $\mathbf{2 0 M H z}$ \\
\hline fir & 0,0827 & 0,0599 & 0,0352 \\
fdct & 0,1078 & 0,0643 & 0,0368 \\
adpcm coder & 0,0810 & 0,0613 & 0,0356 \\
adpcm decoder & 0,0820 & 0,0621 & 0,0361 \\
gaxpy & 0,0879 & 0,0589 & 0,0350 \\
fft & 0,0920 & 0,0600 & 0,0353 \\
autcor & 0,0947 & 0,0609 & 0,0356 \\
dspdorprod & 0,0943 & 0,0605 & 0,0355 \\
dspvecsumsq & 0,0957 & 0,0611 & 0,0357 \\
dspwvec & 0,0957 & 0,0614 & 0,0360 \\
gouraud & 0,0783 & 0,0595 & 0,0351
\end{tabular}

